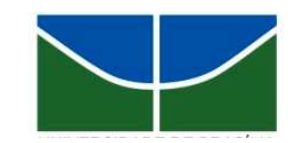

UNIVERSIDADE DE BRASÍLIA

Centro de Excelência em Turismo

Pós-graduação Lato Sensu

Curso de Especialização em Gastronomia e Saúde

\title{
O USO DA TILÁPIA EM UMA ALIMENTAÇÃO SAUDÁVEL
}

Natália Bravim Rinco

Raquel Botelho

BRASÍLIA - DF 


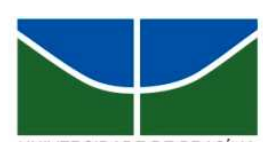

UNIVERSIDADE DE BRASÍLIA

Centro de Excelência em Turismo

Pós-graduação Lato Sensu

Curso de Especialização em Gastronomia e Saúde

\title{
O USO DA TILÁPIA EM UMA ALIMENTAÇÃO SAUDÁVEL
}

\author{
Natália Bravim Rinco
}

Raquel Botelho (Doutora)

Monografia apresentada ao Centro de Excelência em Turismo - CET, da Universidade de Brasília, como requisito parcial à obtenção do grau de Especialista em Gastronomia e Saúde.

Brasília - DF, 2008. 


\section{UNIVERSIDADE DE BRASÍLIA \\ Centro de Excelência em Turismo \\ Pós-graduação Lato Sensu \\ Curso de Especialização em Gastronomia e Saúde}

Natália Bravim Rinco

Aprovado por:

Prof. Orientadora Doutora Raquel Botelho

Prof. MSc. Fabiana Lopes Nalon de Queiroz

Prof. MSc. Verônica Cortez Ginani

Brasília - DF, agosto de 2008. 


\section{AGRADECIMENTOS}

Primeiramente a Deus, por tudo que existe. Aos meus pais Divaldo e Danusia, que foram essenciais para que esse sonho fosse realizado e pelo exemplo de amor e honestidade. Pelo apoio, incentivo e auxílio de minhas irmãs e familiares. Ao meu namorado Thiago, pelo amor, companheirismo e incentivo. A todo o corpo docente do CET/ UnB, que de alguma forma ajudaram e colaboraram para a conclusão deste projeto. A professora Doutora Raquel Botelho, pelo apoio, incentivo e dedicação. 


\section{RESUMO}

Alimentação saudável é tema muito discutido em todo cenário mundial, e que vêm passando por modificações, devido ao surgimento de doenças relacionadas à alimentação dos seres humanos, uma delas, é o surgimento da nova pirâmide alimentar, com novos conceitos, o qual indica que o consumo de carne vermelha, sal e manteiga (óleos de origem animal) sejam reduzidos (consumo moderado) e que peixe, ovo e ave, passem a ser mais presentes nos pratos da população. Os peixes são excelente fonte nutricional e ajudam a combater vários problemas de saúde, e a tilápia (Oreochromis niloticus), peixe de água doce, com características sensoriais próprias, está se tornando popular e ganhando espaço no mercado, devido à facilidade de adaptação de habitat e condições da água. Seguindo esses novos conceitos e avaliando o crescimento do consumo da tilápia, o presente trabalho visa agregar a alimentação saudável ao uso de receitas balanceadas com o filé de tilápia. Foi feito a escolha de duas receitas com o filé, estas foram retiradas de um site da internet, e foi observado quais das dezessete receitas necessitavam de melhoria em sua qualidade nutricional. Foram feitas as modificações necessárias, de acordo com alimentação balanceada, visando reduzir o uso de gorduras (modificando o método de cocção), produtos industrializados e sal $(\mathrm{NaCl})$ das preparações, mas agregando sabor e qualidade. A pesquisa utilizada foi do tipo exploratória e quantitativa. O teste sensorial foi realizado em um restaurante, com um grupo de trinta provadores para cada prato, para tal foi utilizada escala hedônica de 7 pontos. As preparações tiveram ótima aceitação, o Filé de Tilápia com palmito e molho branco de $100 \%$ e o Filé de Tilápia à parmegiana com $89,5 \%$.

(Palavras chave: Alimentação, saudável, nutricional, peixe, tilápia, sabor) 


\section{ABSTRACT}

Healthy food is a much discussed topic throughout the world, and that comes through changes due to the emergence of diseases related to food for human beings, one of them is the emergence of the new food pyramid, with new concepts, suggesting that the consumption of red meat, butter and salt (oils of animal origin) are reduced (moderate consumption) and the consumption of fish, egg and poultry, will be more present in the meals of the population. Fishes are excellent nutritional source and help to combat various health problems, and tilapia (Oreochromis niloticus), fresh water fish, with sensory own characteristics, is becoming popular and gaining space on the market because of the easy adaptation of habitat and conditions of the water. Following these new concepts and assessing the growth of consumption of tilapia, this work aims to add healthy eating to the use of revenue balanced with the fillet of tilapia. It made the choice of two revenue with the fillet, they were taken from a web site, which was observed and seventeen of revenue needed improvement in their quality. We made the necessary changes, according to balanced nutrition, to reduce the use of fats (modifying the method of cooking), industrial products and salt $(\mathrm{NaCl})$ of preparations, but adding flavor and quality. The research of the type used was exploratory and quantitative. The sensory test was conducted in a restaurant with a group of thirty tasters for each dish, for that was used hedônica scale of 7 points. The preparations have had great acceptance, the Filé of Tilápia with white sauce and palm of $100 \%$ and Filé of Tilápia to parmegiana with $89.5 \%$.

(Keywords: Food, health, nutrition, fish, tilapia, taste) 


\section{LISTA DE FIGURAS}

Figura 1. Pirâmide alimentar tradicional .................................................14

Figura 2. Nova pirâmide alimentar..........................................................15

Figura 3. Tilápia do Nilo (Oreochromis niloticus) …….................................20

Figura 4. Tilápia do Nilo Vermelha (Oreochromis niloticus) ............................20

Figura 5. Tilápia azul (Oreochromis aureus) ………...................................21

Figura 6. Tilápia de Moçambique (Oreochromis mossambicus)........................21

Figura 7. Tilápia de Zanzibar (Oreochromis urolepis hornorum)......................21

Figura 8. Filé fresco de Tilápía do Nilo........................................................23

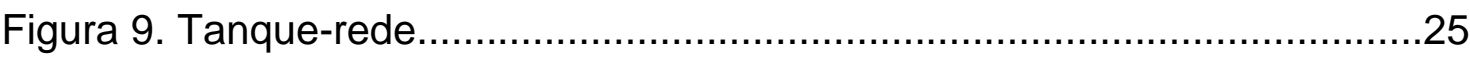

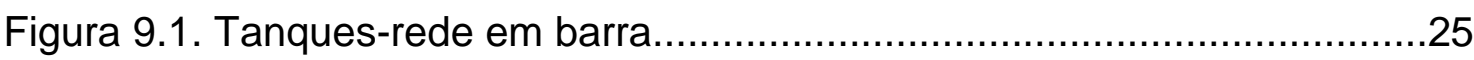

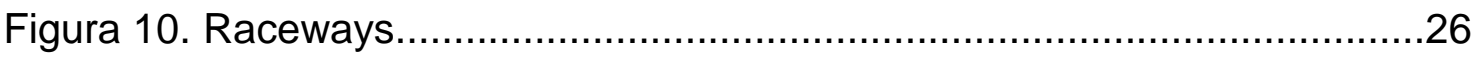

Figura 11. Gráfico de distribuição de Macronutrientes ..................................36

Figura 12. Tabela de escores de diferente formulação de filé de tilápia com

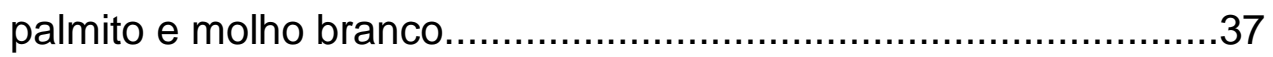

Figura 13. Gráfico aranha da análise sensorial do filé de tilápia com palmito e

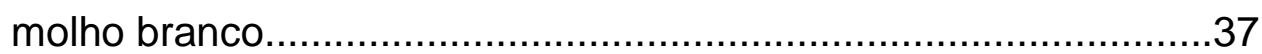

Figura 14. Tabela de escores de diferentes formulações de filé de tilápia à

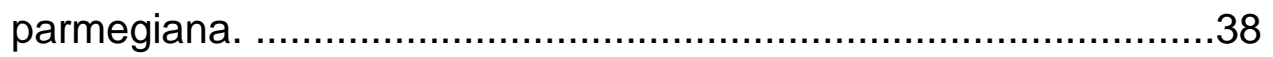

Figura 15. Gráfico aranha da análise sensorial do filé de tilápia à parmegiana. 


\section{LISTA DE TABELAS}

Tabela 1 - Aquisição alimentar domiciliar per capita anual, Brasil, segundo os produtos - período 2002-2003

Tabela 2 - Comparação nutricional dos peixes: Tilápia, Abadejo, Merluza e Pescada .23

Tabela 3 - Composição nutricional do filé de tilápia com palmito e molho branco 30

Tabela 4 - Composição nutricional do filé de tilápia à parmegiana 30

Tabela 5-Composição nutricional do filé de tilápia com palmito e molho branco

Tabela 6. Composição nutricional do filé de tilápia à parmegiana 33

Tabela 7. Comparação nutricional das receitas de filé de tilápia em $100 \mathrm{~g}$ .35 


\section{SUMÁRIO}

1. INTRODUÇÃO

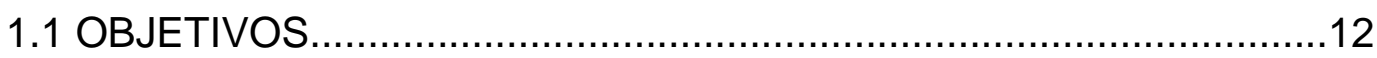

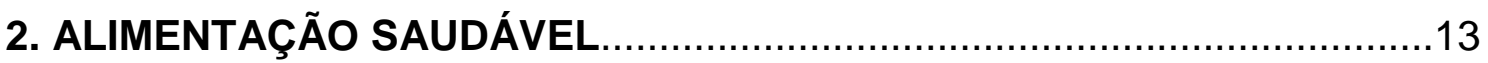

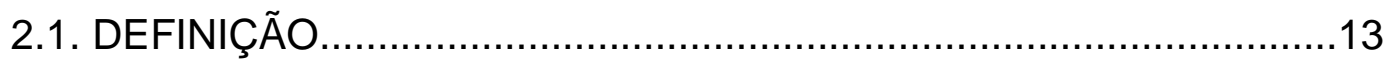

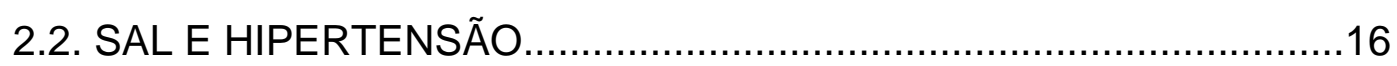

2.3. A IMPORTÂNCIA DO PEIXE NA ALIMENTAÇÃO..........................18

3. TILÁPIA

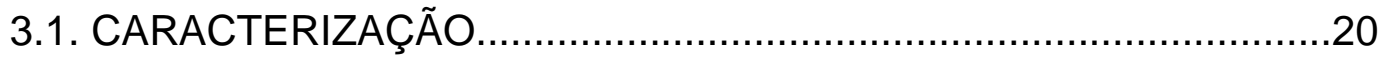

3.2. CARACTERIZAÇÃO NUTRICIONAL DAS TILÁPIAS........................22

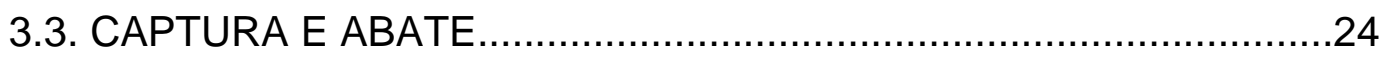

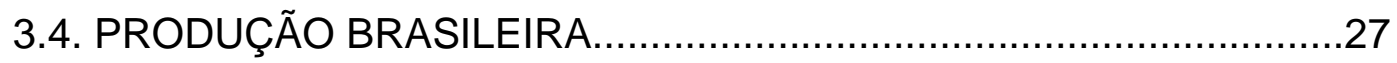

4. METODOLOGIA

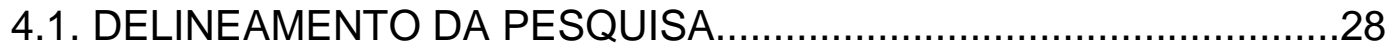

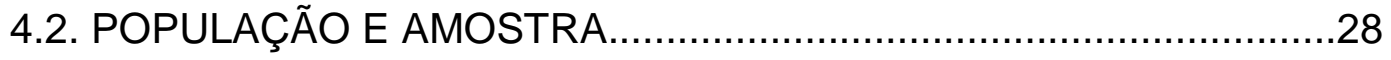

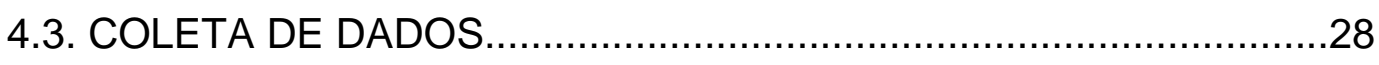

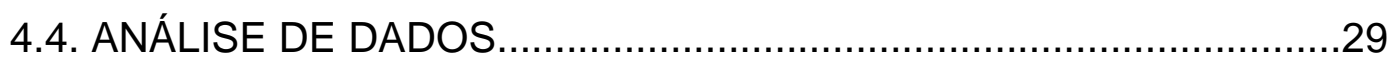

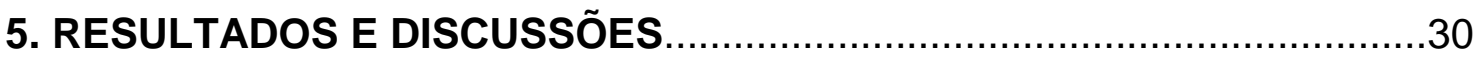

5.1. COMPARAÇÃO NUTRICIONAL DAS RECEITAS...........................34

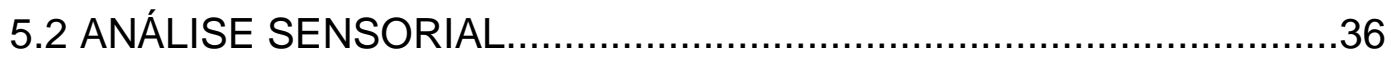

5.2.1. Filé de tilápia com palmito e molho branco modificado..............36

5.2.2. Filé de tilápia à parmegiana........................................................38

6. CONCLUSÃO

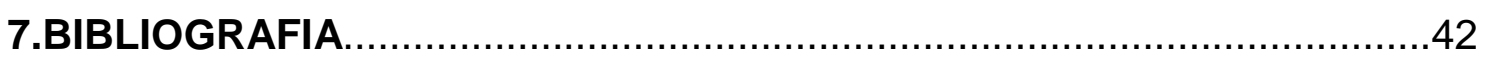

APÊNDICES 


\section{INTRODUÇÃO}

Na segunda metade do século XX, se desenvolveu nas sociedades contemporâneas o hábito do "comer fora" e consumir alimentos industrializados. Por isso os temas alimentação saudável e segurança alimentar são um dos mais discutidos no cenário mundial. A preocupação com o tema se dá, principalmente, pelo fato de estarem surgindo inúmeras doenças associadas à alimentação. Uma parte da população já começa a se preocupar com a saúde, associando sempre a ela uma alimentação balanceada e saudável. Razão pela qual, empresas e indústrias de alimentos estão cada vez mais adaptando e inovando suas técnicas para agradar o consumidor, que a cada dia, preocupa-se mais com saúde e bem estar (AKUTSU et al, 2005).

Os profissionais da área de saúde vêm fazendo uma campanha freqüente para que a população brasileira se torne adepta de hábitos saudáveis, o que inclui uma dieta adequada, com alimentos frescos, menos industrializados, com baixo percentual de gordura e menor consumo de sal $(\mathrm{NaCl})$. Tais medidas visam evitar o surgimento ou o agravamento de doenças associadas a hábitos não-saudáveis, como a hipertensão, por exemplo (SOCIEDADE BRASILEIRA DE CARDIOLOGIA, 2008).

A inclusão de peixes no cardápio do ser humano é fundamental para que tais objetivos sejam atingidos, pois são excelentes fontes de nutrientes, com grande quantidade de proteína e baixo teor de gordura. Por isso, os nutricionistas e os médicos indicam o consumo freqüente deste produto. $\mathrm{Na}$ antiga pirâmide alimentar a quantidade a ser consumida de peixe estava no mesmo patamar da carne vermelha, mas diversos fatores levaram 0 departamento de nutrição da Escola de Saúde Pública da Universidade Harvard a elaborar uma nova pirâmide alimentar, onde o peixe passou para uma posição mais destacada, devendo ser consumido com mais freqüência, enquanto a carne vermelha deve ser consumida moderadamente (USDA, 2004).

Os profissionais da área indicam o aumento do consumo de peixe pela população porque além de ser um ótimo alimento para quem quer controlar os níveis de colesterol, controlar o peso, a carne apresente excelente qualidade nutricional. Esses fatores vêm gerando um aumento da atividade da 
piscicultura mundial. No Brasil, devido condições climáticas favoráveis para criação de diversos tipos de peixe, tal atividade está crescendo em grandes dimensões. Dentre as espécies mais cultivadas está a Tilápia do Nilo (Oreochromis niloticus), que ocupa posição de destaque porque é um peixe com fácil adaptação de clima, ambiente, qualidade da água e, além disso, sua carne possui aparência e sabor agradável e possui baixo índice de gordura (FILHO, 2003).

É importante frisar que o peixe é um alimento muito saudável, mas é preciso cautela na hora da preparação, pois a adição de temperos (sal, tempero completo, caldos industrializados) e gorduras em excesso (azeite, óleos, leites e derivados), pode acabar tornando o prato uma opção nãosaudável (BRASIL, 2005).

\subsection{OBJETIVO GERAL}

Avaliar a aceitação de duas receitas modificadas de filé de tilápia.

\subsection{OBJETIVOS ESPECÍFICOS}

Modificar as receitas para atender os conceitos atuais de alimentação saudável quanto à composição em macronutrientes e sódio.

Verificar por meio de análise sensorial se as preparações modificadas podem agregar sabor e qualidade nutricional. 


\section{ALIMENTAÇÃO SAUDÁVEL}

\subsection{DEFINIÇÃO}

De acordo com o Ministério da Saúde (BRASIL, 2005), a alimentação não se delineia enquanto uma "receita" pré-concebida e universal para todos, pois deve respeitar alguns atributos coletivos $\mathrm{e}$ individuais impossíveis de serem quantificados de maneira prescritiva. Contudo, identificam-se alguns princípios básicos que devem reger esta relação entre as práticas alimentares e a promoção da saúde e a prevenção de doenças. Uma alimentação saudável deve ser baseada em práticas alimentares assumindo a significação social e cultural dos alimentos como fundamento básico conceitual.

Os alimentos são essenciais para a vida, pois são eles que nos fornecem os nutrientes necessários para que o organismo se forme, se mantenha e não adoeça. Adotar uma alimentação balanceada é fundamental para o bom funcionamento do organismo e para ter uma vida saudável (SAÚDE TOTAL, 2007).

Uma alimentação balanceada não é fator único e fundamental para afirmar que uma pessoa tenha uma vida saudável. É muito importante que haja interação do consumo alimentar balanceado, atividade física, e de hábitos saudáveis, como por exemplo, não fumar, não ingerir ou pelo menos diminuir o consumo de bebidas alcoólicas e evitar o consumo de sal, a fim de favorecer a redução de danos à saúde (BRASIL, 2005).

Alimentação balanceada consiste na ingestão balanceada de todos os grupos de alimentos presentes na pirâmide alimentar, na qual é baseada em alimentos funcionais, ou seja, alimentos que exercem funções importantes além da nutrição, como diminuição do colesterol sangüíneo, prevenção do aparecimento de câncer, etc. Assim, uma proposta de alimentação saudável, para prevenção das doenças crônicas não transmissíveis, há de propor dietas que estejam ao alcance da sociedade como um todo, e que tenham um impacto sobre os mais importantes fatores relacionados às várias doenças.

Durante a década de 90, quando o Departamento de Agricultura dos Estados Unidos (USDA), resolveu usá-la como referência em programas de 
alimentação a pirâmide alimentar passou a ser cultuada também por nutricionistas e praticantes de dieta do mundo inteiro. A pirâmide alimentar tradicional (Figura 1), como é chamada, aparecia com a base ampla formada por pão, cereais, arroz e macarrão. No andar de cima, seguiam-se frutas e hortaliças. Depois, para consumo mais restrito, vinham os laticínios (leite, queijo e iogurte), ao lado do grupo da carne, frango, peixe, feijão e ovos. No topo, pontudo e minguado, havia gorduras, doces e óleos. Dessa maneira, estabelecia-se uma equação para a comida saudável, rica em carboidratos (USDA, 2004).

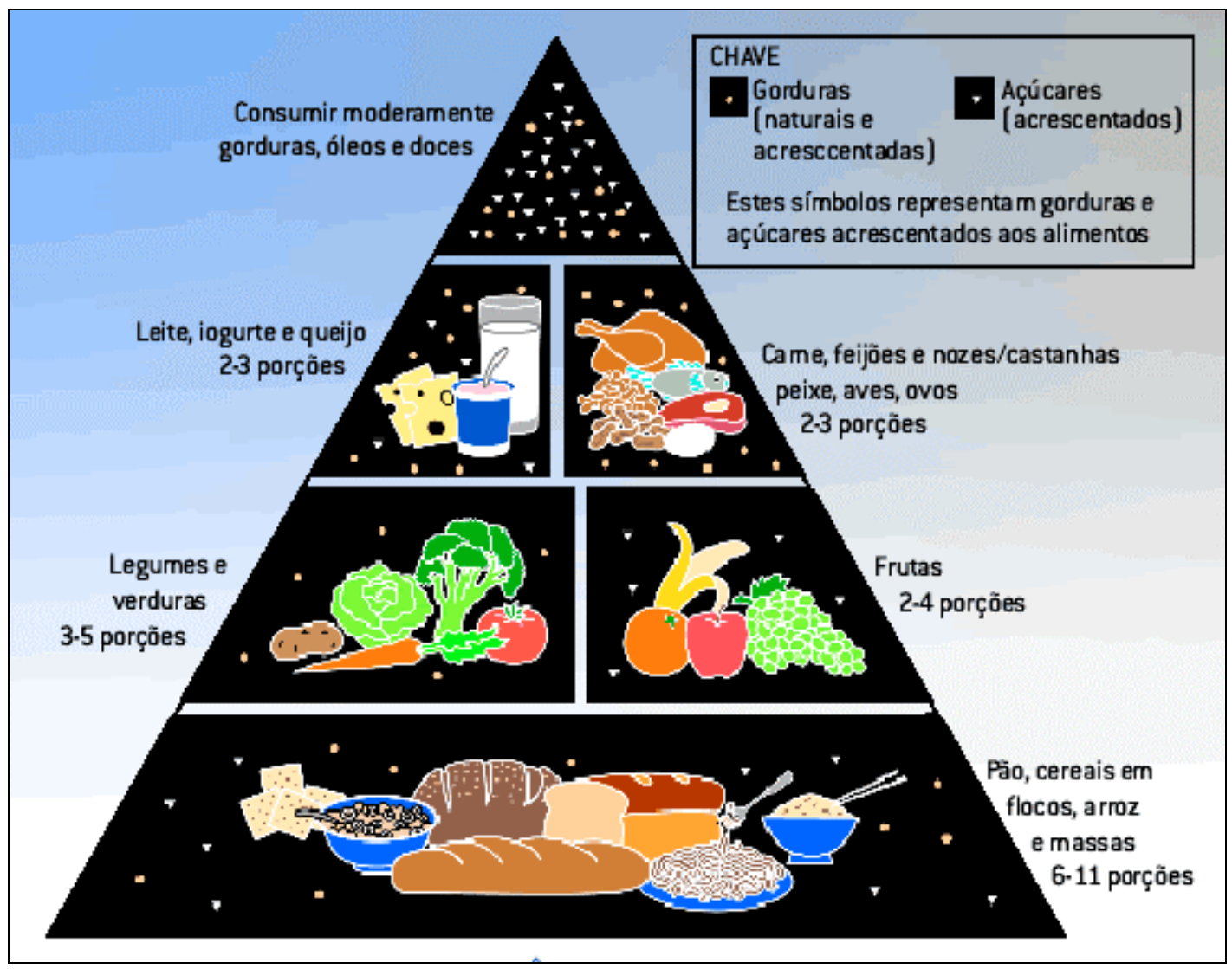

Figura 1. Pirâmide alimentar tradicional

Depois de mais de uma década em vigor, uma série de motivos levaram uma equipe liderada por Walter Willett, chefe do departamento de nutrição da Escola de Saúde Pública da Universidade Harvard, a elaborar uma nova pirâmide alimentar (Figura 2), esta com a base constituída por exercícios físicos e o controle de peso. Depois os carboidratos integrais (pães e arroz integrais) juntamente com óleos vegetais. Logo acima, estão as hortaliças e as 
frutas. Depois, estão as castanhas, o amendoim e as leguminosas (feijão, ervilha e grão de bico). Em seguida, estão peixes, frango e ovos. No topo da pirâmide encontram-se os laticínios ou suplementos de cálcio, e por último, arroz branco, pães brancos, batata, macarrão e doces, além da carne vermelha e a manteiga (USDA, 2004).

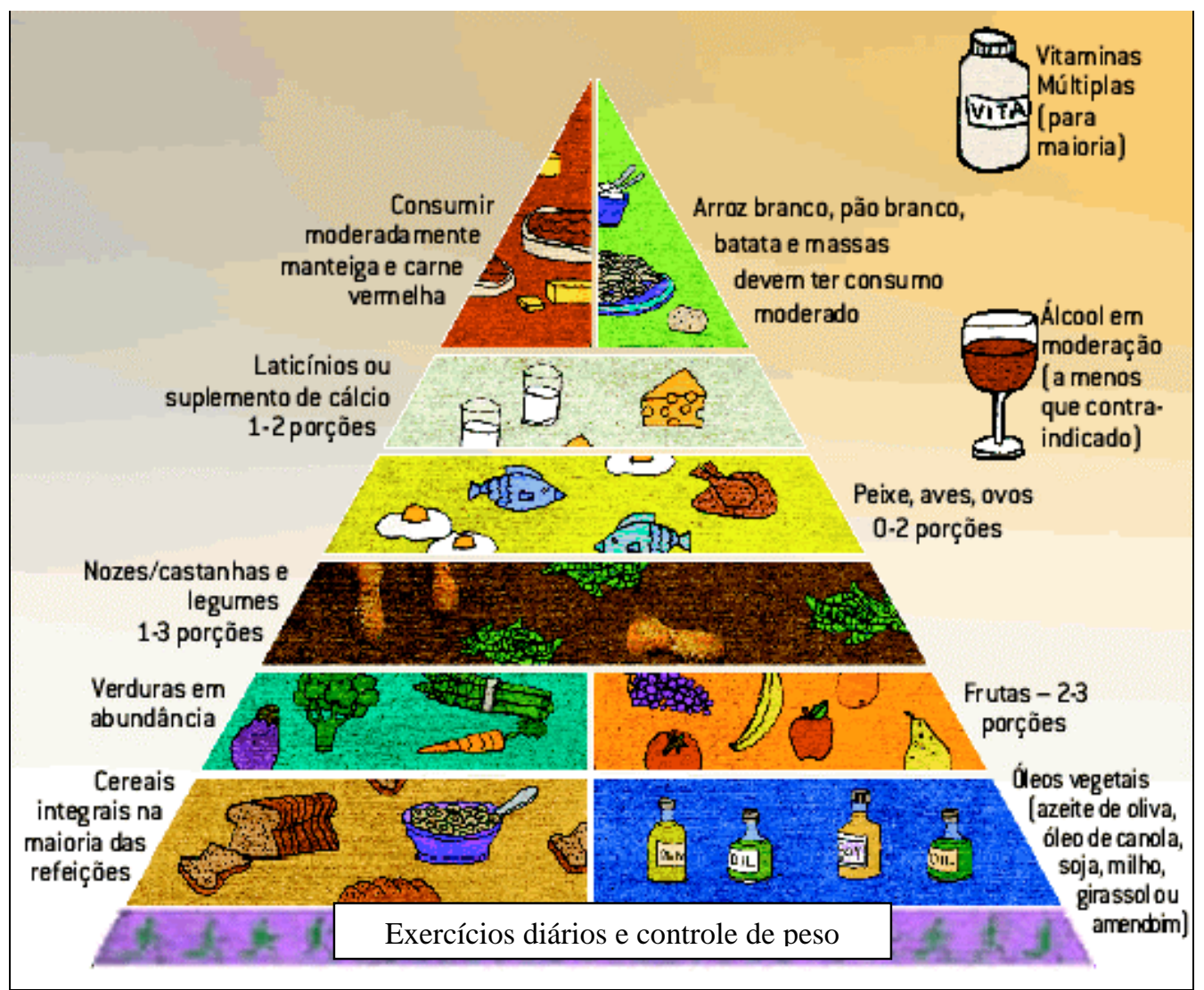

Figura 2. Nova pirâmide alimentar

Observando as duas figuras acima, o consumo de peixe na pirâmide tradicional está no mesmo andar do grupo da carne vermelha, já na nova pirâmide peixes, aves e ovos estão no mesmo grupo e o consumo, diferente da antiga, deve ser superior ao de carne vermelha, ao qual se indica consumir moderadamente.

Adotar uma alimentação balanceada é fundamental para o bom funcionamento do organismo e para ter uma vida saudável. Todos os alimentos podem fazer parte de uma alimentação equilibrada, eles devem combinar uns com outros com o objetivo de atender as necessidades de energia e nutrientes 
do organismo. A possibilidade de obter os nutrientes de que o organismo necessita depende da quantidade e diversidade de alimentos consumidos.

Alimentos como açúcar, as gorduras e o sal podem ser encontrados em vários grupos, por já estarem presente naturalmente nos alimentos. A ingestão particular desses alimentos, como por exemplo: o sal de cozinha deve ser alvo de atenção, uma vez que o seu excesso pode acarretar vários comprometimentos à saúde (NATURALSPA, 2006).

\subsection{SAL E HIPERTENSÃO}

A hipertensão arterial sistêmica (HAS), mais conhecida como "pressão alta", tem sido apontada como fator de risco mais importante para o surgimento de doenças cardiovasculares. Segundo a Organização Mundial de Saúde (OMS, 2006), a hipertensão vem sendo apontada como uma das 10 causas de morte no mundo, e vista como um problema de saúde pública no Brasil. A prevalência estimada de hipertensão no Brasil atualmente é de 35\% da população acima de 40 anos. Isso representa em números absolutos um total de 17 milhões de portadores da doença, segundo estimativa de 2004 do Instituto Brasileiro de Geografia e Estatística (IBGE, 2004).

O MS (BRASIL, 2007) apresentou algumas medidas adotadas destinada à Promoção da Alimentação Saudável e atualmente contemplada no Guia Alimentar para a População Brasileira. Nesta apresentação foram abordados assuntos como as doenças cardiovasculares, que lideram as causas de óbito no país. Isto está relacionado ao consumo excessivo de sódio pela população, um dos principais fatores para o desenvolvimento da hipertensão arterial e complicações cardiovasculares decorrentes.

A pressão alta ocorre porque os vasos nos quais circulam o sangue se contraem e fazem com que a pressão do sangue se eleve. A pessoa é considerada hipertensa quando a sua pressão arterial estiver maior ou igual a 140/90 mmHg (ou 14 por 9). Essa pressão alta acaba causando danos à camada interna dos vasos, fazendo com que se tornem endurecidos e estreitados, podendo, com o passar dos anos, entupir ou se romper. Quando não tratado pode levar à ocorrência de derrames (AVC), infarto, insuficiência cardíaca e insuficiência renal (SBC, 2008). 
Nos últimos 50 anos, o uso do sal na alimentação tem sido cada vez mais desaconselhado e provavelmente a maioria das pessoas considera o sal nocivo ou mesmo perigoso para a saúde. Como o sal tem tendência para atrair líquidos, pode aumentar a pressão arterial e conduzir à hipertensão. Na realidade, a maioria das pessoas utiliza demasiado sal, particularmente sob a forma de "sal escondido" tão comum nos alimentos modernos como batatas fritas, pão refinado, nos alimentos "fast food" e nos derivados de carne (charque, salsicha, lingüiça, presuntos e outros embutidos) (INSTITUTO AHAU, 2008).

As informações disponíveis sobre consumo de sal no Brasil indicam que a média do consumo de sal em 2000 era de 16,76 g/dia, em uma tendência crescente. Prevendo que $10 \%$ deste total refere-se à alimentação animal e desperdício, pode-se inferir um consumo diário por pessoa de 15,08 g de sal. Quando compara-se este valor com a média de consumo de sal em países industrializados, que é de 8-9 g/dia, observa-se que o Brasil apresenta um dos níveis mais altos do mundo (BRASIL, 2004). Há ainda dados da Pesquisa de Orçamentos Familiares 2002-2003 (IBGE, 2004) que indicam por meio das despesas com aquisição de sal para o consumo do domicílio, que a média estimada de consumo é de $9,6 \mathrm{~g} /$ pessoa/dia.

Com base nestas informações, estima-se que o consumo médio de sal pela população brasileira deve ser reduzido, pelo menos, à metade, para atender ao patamar máximo de consumo recomendado pela Organização Mundial da Saúde, isto é, $6 \mathrm{~g}$ de sal/per capita/dia. O Guia Alimentar da População Brasileira adota o consumo de $5 \mathrm{~g}$ de sal iodado por dia, para uma pessoa adulta, como recomendação para uma alimentação saudável (MS, 2007).

As pessoas com maior risco de ficarem hipertensas são aquelas que ingerem bebidas alcoólicas, que possuem histórico na família, que se encontram com excesso de peso, que usam muito sal na alimentação, que são diabéticos, não praticam atividades físicas regularmente e não possuem uma alimentação saudável (SBC, 2008).

Diminuir o sal nas preparações não deve ser sinônimo de comida sem gosto. Para isto, as ervas são excelentes aliadas, pois são aromáticas e saborosas. Basta variar as ervas adicionadas como estragão, orégano, sálvia, 
aipo, alecrim, tomilho, manjericão, salsinha e cebolinha (SAÚDE TOTAL, 2008).

A adição de peixe na alimentação de quem deseja reduzir o consumo de sal também é aconselhável, pois além de ser muito saudável e recomendado pelos médicos e nutricionistas, este já possui sabor característico, portanto consegue-se utilizar menos sódio para imprimir sabor a preparação (SAÚDE TOTAL, 2008).

\subsection{A IMPORTÂNCIA DO PEIXE NA ALIMENTAÇÃO}

Algumas espécies de peixe são ricas em ômega-3, que é um tipo de gordura bastante benéfica à nossa saúde. O ômega-3 diminui o risco de doenças cardíacas, aterosclerose (endurecimento das artérias) e ajuda nas inflamações, no desenvolvimento cerebral e na regeneração das células nervosas. E por agir nas células nervosas, o ômega-3, encontrado no peixe, ainda pode ajudar no tratamento da depressão, ansiedade e problemas de sono. Esse tipo de gordura auxilia, ainda, no tratamento da pressão alta, na coagulação do sangue, no alivio das dores causadas pela artrite reumatóide, na proteção da pele contra raios ultravioleta e inflamações (SBC, 2008).

O peixe é um excelente alimento para o desenvolvimento escolar de crianças e adolescentes e não pode faltar na alimentação dos idosos, já que diminui o risco de desenvolvimento do mal de Alzheimer, demência e cansaço mental, além de reduzir hormônios do tecido adiposo e controlar o apetite. Está comprovado que o consumo regular de peixe ajuda a evitar o desenvolvimento de doenças cardíacas e a morte súbita por ataque de coração (SBC, 2008).

$\mathrm{Na}$ nova pirâmide alimentar o peixe ganhou destaque, sendo fundamental introduzi-lo na alimentação da população mundial, pois o peixe é ótimo alimento para quem quer controlar o nível de colesterol no sangue, perder peso, ter um sistema imunológico mais eficaz e maior longevidade.

De acordo com a POF (PESQUISA DE ORÇAMENTOS FAMILIARES, 2003), o grupo das carnes, vísceras e pescados é o que mais pesa nas despesas $(18,34 \%)$ dos brasileiros. A aquisição alimentar domiciliar per capita (Tabela 1) de aves e ovos, carnes (bovinas, suínas e de outros animais), pescados e vísceras, é expressa pelos resultados da POF. 
Tabela 1 - Aquisição alimentar domiciliar per capita anual, Brasil, segundo os produtos - período 2002-2003

\begin{tabular}{|l|c|}
\hline \multicolumn{1}{|c|}{ PRODUTOS } & $\begin{array}{c}\text { AQUISIÇÃO ALIMENTAR DOMICILIAR } \\
\text { PER CAPITA ANUAL (KG) }\end{array}$ \\
\hline Aves e ovos & 15,577 \\
\hline $\begin{array}{c}\text { Carnes (bovinas, suínas e de } \\
\text { outros animais) }\end{array}$ & 25,237 \\
\hline $\begin{array}{c}\text { Pescados } \\
\text { Vísceras }\end{array}$ & 4,587 \\
\hline Fonte: IBGE, Diretoria de Pesquisas, Coordenação de Índices de Preços, Pesquisa de
\end{tabular}

Orçamentos Familiares 2002-2003. Nota: As quantidades de produtos adquiridos na forma líquida foram transformadas em $\mathrm{kg}$, considerando-se volume igual a peso.

$\mathrm{Na}$ tabela acima, verifica-se que, no Brasil, a aquisição de carnes (bovinas, suínas e de outros animais) é bastante superior ao de aves e ovos, que por sua vez, é muito superior ao de pescados, e o consumo de vísceras fica com a menor quantidade. É importante observar essa tabela para ver que os padrões da nova pirâmide alimentar, a qual enfatiza o consumo moderado de carne vermelha, não estão sendo praticados pela população brasileira, pois, a carne vermelha e a de outros animais continuam sendo o prato principal. No Brasil, o consumo de peixes está em ascensão, o que significa uma melhora na qualidade nutricional do prato. 


\section{TILÁPIA}

\subsection{CARACTERIZAÇÃO}

As tilápias são ciclídeos nativos do continente Africano e da Palestina, com cerca de 75 espécies válidas, que têm sido utilizadas na piscicultura desde o ano 2000 a.C. Essas espécies têm sido consideradas importantes não só pelo seu valor nutricional, mas também pelo seu desempenho como agente biológico no combate a mosquitos e ervas daninhas aquáticas (FAO, Food and Agriculture Organization, 2003).

Apesar dessa grande variedade de espécies, apenas quatro conquistaram destaque na aqüicultura mundial, todas elas do gênero Oreochromis. No entanto a espécie mais procurada pelos piscicultores do mundo é a tilápia do Nilo (Oreochromis niloticus) (Figura 3), devido ao seu crescimento acelerado, reprodução mais tardia e alta prolificidade. A tilápia do Nilo possui uma linhagem vermelha (Figura 4), que é originária de um grupo de peixes coletados no Lago Manzala no Egito. Elas possuem o fenótipo vermelho dominante. Isso significa que o cruzamento de peixes vermelhos com os peixes de coloração normal resulta em descendentes $100 \%$ vermelhos. As outras três espécies mais cultivadas são: a tilápia azul (Oreochromis aureus (Figura 5); a tilápia de Moçambique (Oreochromis mossambicus) (Figura 6) e a tilápia de Zanzibar (Oreochromis urolepis hornorum) (Figura 7) (KUBITZA, 2000).

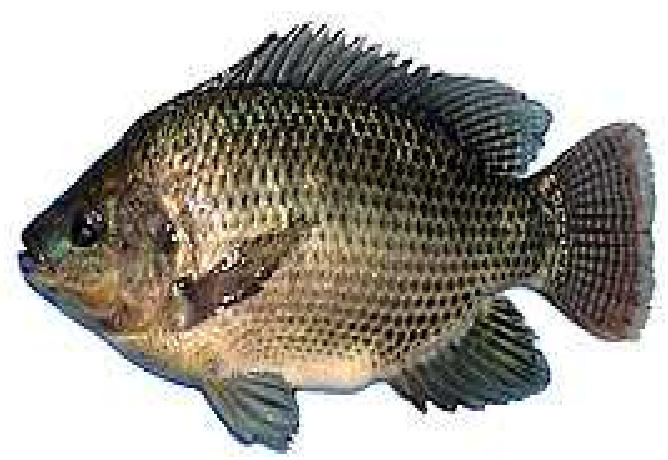

Figura 3. Tilápia do Nilo (Oreochromis niloticus)

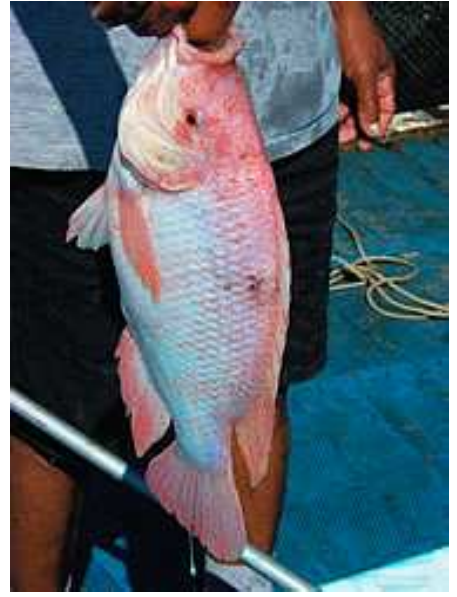

Figura 4. Tilápia do Nilo Vermelha (Oreochromis niloticus) 


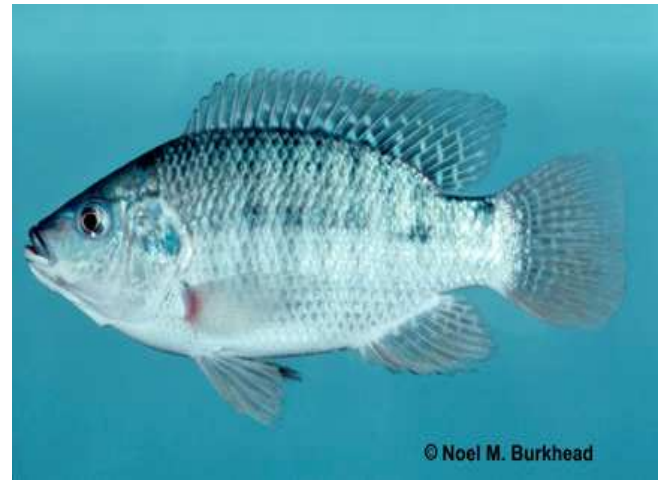

Figura 5. Tilápia azul (Oreochromis aureus)

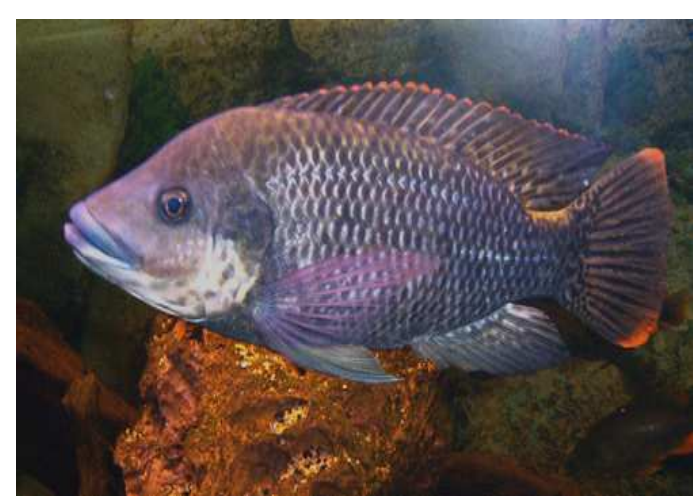

Figura 6. Tilápia de Moçambique (Oreochromis mossambicus)

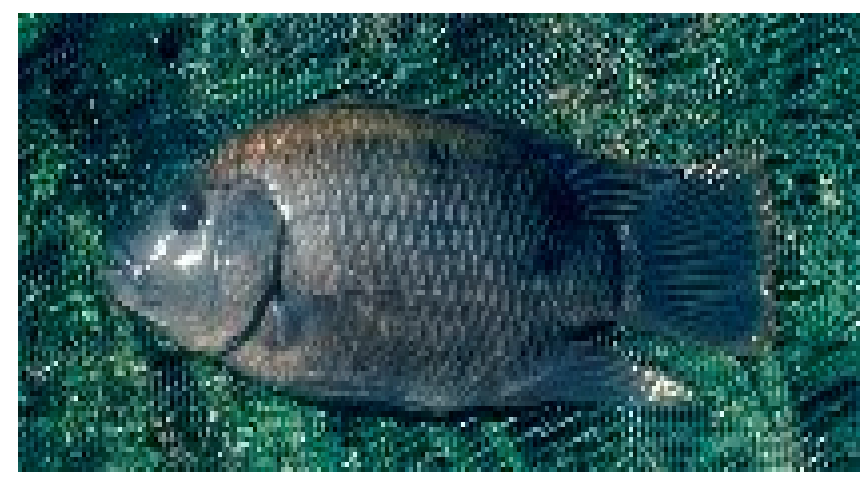

Figura 7. Tilápia de Zanzibar (Oreochromis urolepis hornorum)

A Oreochromis niloticus, segundo Brugger et al (2000), tem sido etiquetada como o "novo pescado branco". Os autores enfatizam que as tilápias destacam-se por possuírem boas características organolépticas e nutricionais, possuindo carne saborosa, com baixo teor de gordura (até $0,9 \mathrm{~g} / 100 \mathrm{~g}$ de carne), calorias ( $95 \mathrm{Kcal} / 100 \mathrm{~g}$ de carne) e ausência de espinhas na forma de "Y" (mioceptos).

As tilápias, peixes de água doce, são reconhecidas por se adaptarem a diferentes condições de qualidade de água. Possuem capacidade de suportar baixas concentrações de oxigênio. Os valores de $\mathrm{pH}$ aconselháveis para obtenção de melhores resultados devem estar entre 6,0 e 8,5 e a concentração de amônia estar abaixo de 0,24 mg/l, porém convivem muito bem com uma faixa bastante ampla de acidez e alcalinidade na água, mas valores muito extremos como inferior a 3,5 ou acima de 12 causam mortalidade em menos de 6 horas de exposição. Além disso, se reproduzem em águas 
salobras e salgadas e toleram altas concentrações de amônia tóxica comparadas à maioria dos peixes cultivados (KUBITZA, 2000).

A tilápia nilótica atinge a primeira maturação gonadal aos quatro ou cinco meses de idade, podendo a partir de então desovar a cada dois meses durante todo o período reprodutivo. A época de desova ocorre durante os meses em que a temperatura da água permanece mais elevada, superior a $24^{\circ} \mathrm{C}$. O peixe nasce sem sexo, define-o ao consumir seus primeiros alimentos que, sabiamente, a natureza impregnou com os fatores indutores da sexualidade. Nesse ponto, o homem desenvolveu a tecnologia da reversão sexual, faz o peixe nascer num ambiente onde só existem alimentos impregnados com os fatores do sexo masculino. Dessa maneira, é possível se obter até $100 \%$ de indivíduos machos, que oferecem maior quantidade de carne, em menor tempo de cativeiro (FILHO, 2003).

Os métodos de controle de reprodução nas tilápias é algo que tem causado grandes dificuldades no cultivo desta espécie, devido à prolificidade precoce da reprodução, tornando superpovoada a unidade de cultivo. Isso acarreta uma enorme competição pelo alimento, causando assim, resultados insatisfatórios de crescimento (BRESSAN, 2001).

\subsection{CARACTERIZAÇÃO NUTRICIONAL DAS TILÁPIAS}

Os alimentos podem compor 40 a $70 \%$ do custo de produção de tilápias, dependendo do sistema de cultivo empregado. Através dos alimentos disponíveis ou oferecidos, os peixes devem obter suficientes quantidades de nutrientes essenciais de forma a garantir a normalidade de seus processos fisiológicos e metabólicos, assegurando adequado crescimento, saúde e reprodução. Dessa forma, é reconhecido que os peixes apresentam exigências em pelo menos 44 nutrientes essenciais, assim reunidos: (1) Água; (2) Aminoácidos essenciais; (3) Energia; (4) Ácidos graxos essenciais; (5) Vitaminas; (6) Minerais; (7) Outros nutrientes (carotenóides, palatabilizantes, entre outros) (KUBITZA, 2000).

Comparadas a muitos outros peixes, as tilápias apresentam filé magro, com 3 a $8 \%$ de gordura, dependendo do tamanho do peixe, do sistema de cultivo, da composição da dieta e do manejo alimentar. Além desses fatores existem outros motivos para a escolha desse peixe, o sabor suave da carne, 
cada vez mais procurado, inclusive para o preparo de sashimis (peixe cru culinária japonesa), e por ser um peixe de fácil manuseio na cozinha (Figura 8).

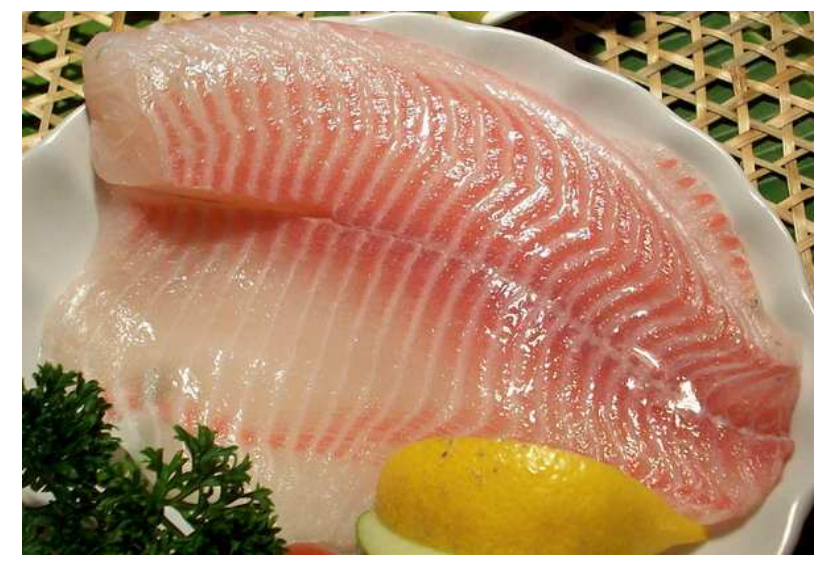

Figura 8. Filé fresco de Tilápía do Nilo

O pescado é uma excelente fonte de proteínas de alto valor biológico e de aminoácidos essenciais, sendo especificamente rico em lisina, um aminoácido limitante em cereais, como arroz, milho e farinha de trigo. (FILHO, 2003). A carne da tilápia apresenta características nutricionais excelentes e para verificar essa qualidade frente a outros peixes muito consumidos no Brasil, a Tabela 2, apresenta a comparação da composição nutricional da Tilápia, do Abadejo, da Merluza e da Pescada.

Tabela 2 - Comparação nutricional dos peixes: Tilápia, Abadejo, Merluza e Pescada.

\begin{tabular}{|l|c|c|c|c|c|c|c|c|}
\hline \multicolumn{10}{|c|}{ Porção 100 g (1 filé) } \\
\hline & \multicolumn{2}{|c|}{ TILÁPIA } & \multicolumn{2}{c|}{ ABADEJO } & \multicolumn{2}{c|}{ MERLUZA } & \multicolumn{2}{c|}{ PESCADA } \\
\cline { 2 - 9 } & Porção & $\% V D\left({ }^{*}\right)$ & Porção & $\%$ VD(*) & Porção & $\%$ VD( $\left.{ }^{*}\right)$ & Porção & $\%$ VD( $\left.{ }^{*}\right)$ \\
\hline Energia & $95 \mathrm{kcal}$ & 4,75 & $90 \mathrm{kcal}$ & 4 & $142 \mathrm{kcal}$ & 6 & $90 \mathrm{kcal}$ & 4 \\
\hline Carboidratos & $0 \mathrm{~g}$ & 0 & $0 \mathrm{~g}$ & 0 & $0 \mathrm{~g}$ & 0 & $0 \mathrm{~g}$ & 0 \\
\hline Proteínas & $20 \mathrm{~g}$ & 26,6 & $19 \mathrm{~g}$ & 38 & $22 \mathrm{~g}$ & 44 & $19 \mathrm{~g}$ & 38 \\
\hline Lipídios & $1,67 \mathrm{~g}$ & 3,3 & $1 \mathrm{~g}$ & 2 & $5 \mathrm{~g}$ & 6 & $2 \mathrm{~g}$ & 3 \\
\hline Sódio & $38,3 \mathrm{mg}$ & 1,67 & $285 \mathrm{mg}$ & 12 & $74 \mathrm{mg}$ & 3 & $193 \mathrm{mg}$ & 8 \\
\hline
\end{tabular}

*\% Valores com base em uma dieta de $2.000 \mathrm{kcal}$ ou $8.400 \mathrm{kj}$. Seus valores diários podem ser maiores ou menores dependendo de suas necessidades energéticas. ${ }^{* *}$ VD não estabelecido.

Fonte: www.peixenarede.com.br 
Fazendo uma relação entre os quatro peixes da tabela de composição nutricional foi constatado que:

- A tilápia apresenta apenas 5 kcal a mais em relação ao Abadejo e à Pescada e 47 kcal a menos que a Merluza;

- Quanto às proteínas, os peixes têm níveis muito parecidos;

- Apesar de todos os peixes apresentarem níveis muito baixos de lipídios, o Abadejo é o único que possui uma quantidade menor de lipídios que a Tilápia (apenas 0,67g/100g);

- A quantidade de sódio presente na tilápia é a menor de todas, chegando a uma diferença de até $219,7 \mathrm{mg}$ (quando comparado com o Abadejo);

Dentre as principais espécies de peixes cultivadas, as tilápias se destacam pela carne de excelente qualidade nutricional e sensorial. Nos Estados Unidos, um painel formado por 10 degustadores profissionais colocou o filé de tilápia cultivada no topo de uma lista, de acordo com o critério satisfação geral, seguidos do filé de salmão Coho, da truta arco-íris, do bagredo-canal, do híbrido "striped bass" e, finalmente, do "largemouth bass" e da carpa capim (Chambers IV; Robel 1993). Estes profissionais fizeram uma descrição bem detalhada dos diferentes aspectos de textura e sabor do filé da tilápia. Em síntese, este peixe apresenta filé sem espinho, de cor branca, textura firme, aspecto fibroso e suculento. O sabor é delicado. Todas estas características fazem da tilápia um peixe destinado aos bons "gourmets", ou seja, se ajusta aos mais diferentes tipos de temperos, formas de preparo e apresentação (KUBITZA, 2000).

\subsection{CAPTURA E ABATE.}

Os tanques para criação de peixe têm, em média, 1,5 metros de profundidade. São tanques em terra batida onde se concentram, na maioria das vezes, cinco indivíduos por metro cúbico de água. Isso por causa da concentração de oxigênio dissolvido na água. Processos artificiais de aeração permitem a criação de maior número de indivíduos por metro cúbico (PEIXE NA REDE, 2007). 
A produção das tilápias também pode ser feita em tanques-rede ${ }^{1}$ ou em raceways ${ }^{2}$. O cultivo em tanques-rede (Figura 9 e 9.1) vem crescendo no Brasil. As vantagens atribuídas são: Menor investimento inicial para a implantação do empreendimento; Possibilita o aproveitamento dos recursos aquáticos disponíveis; Permite o cultivo de espécies diferentes no mesmo corpo d'água, sem misturá-las; Geralmente reduz a incidência de problemas com mau sabor ou sabor de terra ("off-flavor") nos peixes; E nas tilápias elimina os problemas em relação à reprodução excessiva e à dificuldade de despesca. Uma grande desvantagem do uso dos tanques-rede é o acesso limitado dos peixes ao alimento natural. Já os "Raceways" (Figura 10) podem ser circulares, retangulares ou de outros formatos. $O$ fluxo de água geralmente possibilita $1 \mathrm{a}$ 20 trocas totais por hora. Os resíduos gerados (fezes e sobras de ração) são arrastados juntos com a corrente de água para fora do sistema. Os resíduos sólidos totais geralmente são direcionados para um tanque de decantação (KUBITZA, 2000).

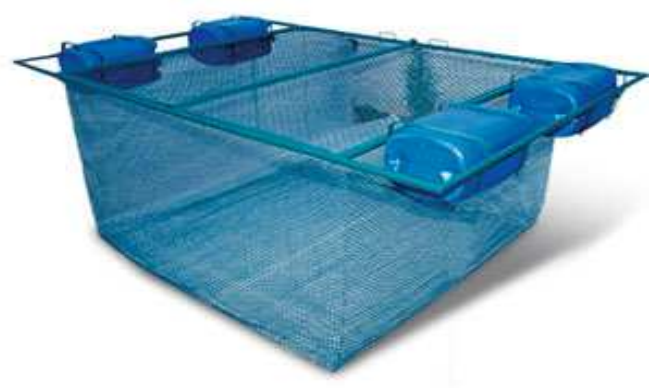

Figura 9. Tanque-rede

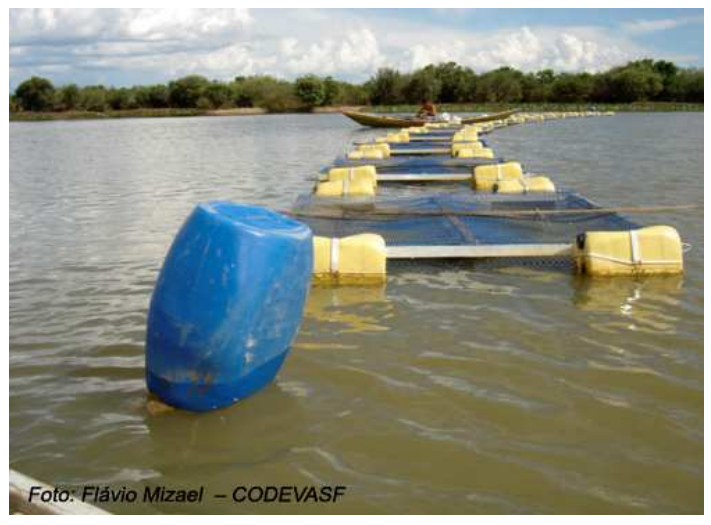

Figura 9.1. Tanques-rede em barra

\footnotetext{
${ }^{1}$ Também chamados de gaiolas, são tanques que servem para aproveitar eficientemente os grandes reservatórios, geralmente reduzindo a incidência de problemas com mau sabor ("offflavor").
}

2 É o nome dado aos tanques com alto fluxo de água. 


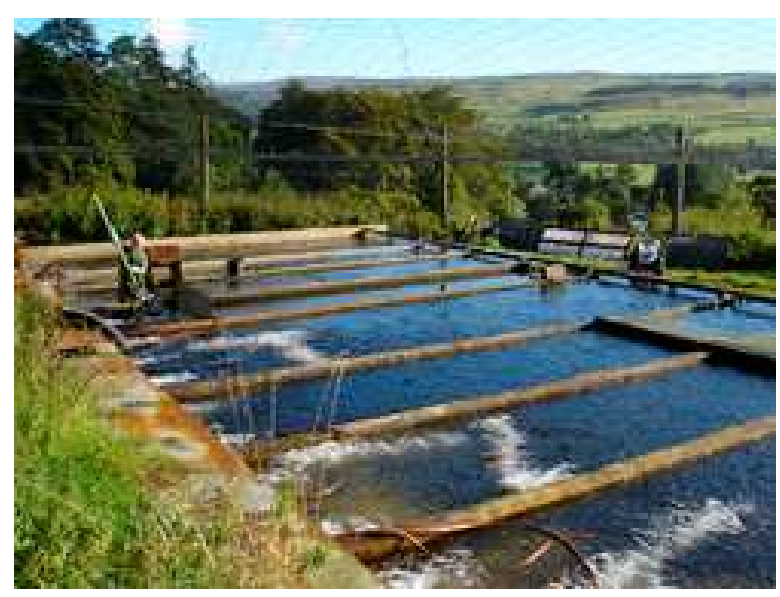

Figura 10. Raceways

Para capturar a tilápia é necessário esvaziar bastante o tanque onde se encontram os peixes e passar a rede para retirada desses. Após a retirada dos peixes do tanque é importante colocá-los em um tanque especial com água limpa e corrente em alta vazão, para a depuração por um período de 18 a 24 horas sem nenhuma alimentação. Nesse processo os peixes vivos passam por uma limpeza externa e esvazia completamente o aparelho digestivo, liberando uma série de toxinas que comprometem a qualidade da carne. A água usada para depuração pode ser esterilizada com cloro, ozônio e outros. Esse processo é essencial, pois reduz as características que levam à baixa aceitação por parte os consumidores como o "off flavor" (sabor de barro ou terra) (BRESSAN, 2001).

O processo de depuração faz os peixes perderem cerca de $10 \%$ do peso com que são retirados dos tanques Após a depuração ocorre o abate por choque térmico em água próxima de zero grau, isso faz com que o sangue do peixe se concentre quase todo na região de sua cabeça. Efetuada a degola, ocorre uma sangria quase total, tornando a carne do filé praticamente isenta da presença de sangue. (BRESSAN, 2001).

As tilápias são abatidas com peso que varia entre 550 a 700 gramas. É o momento em que proporcionam a melhor relação custo/benefício para o piscicultor. Resultam de cada uma delas, dois filés com, aproximadamente, 100 gramas cada um, o suficiente para a refeição de um adulto. Para obter um quilo de filé de tilápia, o produtor precisa de, praticamente, três quilos de peixe vivo. O rendimento de uma boa tilápia chega a $33 \%$ de filé, considerado o peso total do peixe (PEIXE NA REDE, 2007). 


\subsection{PRODUÇÃO BRASILEIRA}

Castagnolli (1992), afirma que a espécie Oreochromis niloticus foi introduzida no Brasil, no Ceará, no ano de 1971, procedente da Costa do Marfim, África, e que recebeu o nome de tilápia-do-Nilo por ser originária da bacia daquele rio.

Progressivamente, o Brasil vem ganhando posições no ranking internacional estabelecido pela FAO (FOOD AND AGRICULTURE ORGANIZATION OF THE UNITED NATIONS). Em 1994, era o $32^{\circ} \mathrm{em}$ produção aqüícola e o 26을 em termos de valores. Em 2004 o Brasil ocupava o $18^{\circ}$ lugar no ranking mundial de produção aqüícola com $0,5 \%$ da produção mundial e $012^{\circ} \mathrm{em}$ termos de receitas geradas com 1,4\% do total (FAO, 2006).

Superadas em produção apenas pelas carpas, as tilápias ocupam posição destacada entre as espécies de água doce cultivadas. Em 1990, a produção mundial de tilápia foi estimada em 855 mil toneladas anuais, sendo que 390 mil toneladas vieram de cultivo (45\%) (KUBITZA, 2000).

A aqüicultura é uma atividade crescente no Brasil, atualmente ela é responsável por $19 \%$ da produção nacional de pescados, no ano de 2004 , a produção anual de tilápia cultivada esteve próxima das 70 mil toneladas (69.078 t), o que representa $25,6 \%$ do total da aqüicultura nacional (IBAMA, 2006). A produção de tilápias já movimenta 105 milhões de dólares por ano no país. O Ceará é o maior pólo de criação brasileiro, com cerca de 18 mil toneladas por ano, o Paraná é o vice-campeão, com 12 mil toneladas, São Paulo ocupa o terceiro lugar, com 9 mil toneladas por ano, Santa Catarina com 7,13 mil toneladas, está praticamente está no mesmo patamar da Bahia que produz cerca de 7,12 mil toneladas por ano (Secretaria Especial de Aqüicultura e Pesca, 2007).

O grupo Tilápia do Brasil está entre os maiores exportadores nacionais de filé de tilápia, $70 \%$ das vendas seguem para os Estados Unidos e Canadá. No Brasil, a rede Pão de Açúcar compra 12 toneladas por mês de filé de tilápia, se destacando entre os maiores clientes do frigorífico (PORTAL DO AGRONEGÓCIO, 2007). 


\section{METODOLOGIA}

\subsection{DELINEAMENTO DA PESQUISA}

A pesquisa é do tipo exploratória e quantitativa, pois esta se mostra apropriada quando existe a possibilidade de medidas quantificáveis e interferências a partir de amostras de uma população. Este tipo utiliza medidas numéricas para testar hipóteses. Foi escolhida por ser esta a primeira pesquisa a estabelecer o valor energético de preparações com a Tilápia, contemplando as diversas perspectivas que o tema exige.

O trabalho foi dividido em três partes: a primeira foi à coleta de dados sobre tilápia e alimentação saudável; a segunda foi a escolha das receitas com filé de tilápia, e depois a modificação das mesmas, calculando o VET das preparações (Apêndice 2), com o intuito de melhorar a qualidade nutricional da preparação, diminuindo os índices de gordura e substituindo ao máximo o sal $(\mathrm{NaCl})$ por condimentos previamente preparados, agregando sabor as preparações; na terceira foi realizada avaliação sensorial das preparações.

\subsection{POPULAÇÃO E AMOSTRA}

O teste foi realizado com um grupo de 30 pessoas para cada prato, somando 60 provadores escolhidos aleatoriamente. Os pratos avaliados foram distribuídos para os clientes de restaurante localizado na cidade de Alto Paraíso - GO, não treinados, com idade acima de 18 anos, sem distinção de sexo. Os provadores utilizaram uma ficha para avaliação sensorial por escala hedônica de categoria de 7 (sete) pontos (Apêndice 1).

\subsection{COLETA DE DADOS}

A revisão bibliográfica foi feita na base de dados da Capes e Scielo bem como livros, sites e apostilas. A pesquisa foi realizada nas línguas portuguesa e inglesa, e as palavras-chave foram: tilápia; piscicultura; alimentação saudável; pirâmide alimentar; nutrição; sal e hipertensão.

As receitas de filé de tilápia foram retiradas de um site da internet (www.globo.com/maisvoce). Primeiramente, duas receitas foram escolhidas entre dezenove disponíveis, e o critério foi verificar quais delas necessitavam 
melhorar sua qualidade nutricional. As receitas foram: filé de tilápia com palmito e molho branco; e filé de tilápia à parmegiana. Estas tinham um teor elevado de sódio, lipídios e calorias. As receitas originais foram testadas, verificando sabor e aparência, para que as modificadas tentassem se aproximar das originais, e se adequassem aos conceitos de alimentação saudável.

Foram elaboradas Fichas Técnicas de Preparação (Apêndice 2) para as duas receitas escolhidas e os ingredientes foram pesados em balança eletrônica Chez com precisão de 1 grama. A análise sensorial foi realizada no restaurante no dia 12/07/2008, sábado, entre 12h00min e 15h00min.

\subsection{ANÁLISE DE DADOS}

Os dados da análise sensorial por escala hedônica foram dispostos em tabela do Excel e em um quadro no Word. $\mathrm{Na}$ análise dos resultados do Excel há uma tabela de comparação das duas receitas, juntamente com a média das notas. A distribuição da freqüência de notas de aceitação e o mapa de preferência foram feitos através de gráficos. 


\section{RESULTADOS E DISCUSSÕES}

Analisando as receitas originais (Tabela 3 e 4) é possível observar o excesso de calorias, de sal e de gorduras, o que não está de acordo com os conceitos de alimentação saudável apresentados neste trabalho.

Tabela 3 - Composição nutricional do filé de tilápia com palmito e molho branco

\begin{tabular}{|c|c|c|c|c|c|}
\hline ITEM & QTDE. & ENERGIA (kcal) & $\mathrm{CHO}(\mathrm{g})$ & PTN (g) & GORD (g) \\
\hline Filé de tilápia (g) & 1000 & 950 & 0 & 20 & 1,7 \\
\hline Palmito (conserva) (g) & 300 & 54 & 11,1 & 4,8 & 0,3 \\
\hline Alcaparra (g) & 20 & 7,40 & 0,97 & 0,54 & 0,97 \\
\hline Azeite (ml) & 30 & 240,92 & 0 & 0 & 31 \\
\hline Cebola (g) & 200 & 63 & 11,2 & 3,2 & 0,60 \\
\hline Limão (ml) & 100 & 29 & 10 & 2 & 0 \\
\hline Sal (g) & 16 & 0 & 0 & 0 & 0 \\
\hline Manteiga (g) & 150 & 996,32 & 0 & 1,7 & 109,95 \\
\hline Requeijão cremoso (g) & 250 & 880 & 0 & 84,5 & 60,65 \\
\hline Farinha de trigo $(\mathrm{g})$ & 60 & 131,70 & 34,27 & 6,34 & 0,25 \\
\hline Leite (ml) & 600 & 378 & 30 & 18,6 & 21 \\
\hline Creme de leite (g) & 200 & 498 & 7 & 5 & 50 \\
\hline TOTAL & 2926 & 4228,34 & 104,54 & 146,68 & 276,42 \\
\hline PORÇÃO & $100 \mathrm{~g}$ & & \multicolumn{2}{|c|}{ VCT PORÇÃO (kcal): } & 144,50 \\
\hline
\end{tabular}

Tabela 4. Composição nutricional do filé de tilápia à parmegiana

\begin{tabular}{|l|c|c|c|c|c|}
\hline \multicolumn{1}{|c|}{ ITEM } & QTDE. & ENERGIA (kcal) & CHO (g) & PTN $(\mathbf{g})$ & GORD (g) \\
\hline Filé de tilápia (g) & 1000 & 950 & 0 & 20 & 1,7 \\
\hline Mussarela (g) & 300 & 974,40 & 0 & 81,6 & 72 \\
\hline Alcaparra (g) & 50 & 17,60 & 2,42 & 1,35 & 0,28 \\
\hline Cebola (g) & 100 & 31,50 & 5,60 & 1,60 & 0,30 \\
\hline Azeite (ml) & 30 & 240,92 & 0 & 0 & 31 \\
\hline Ovos (g) & 100 & 166 & 1,42 & 13,86 & 11,66 \\
\hline Farinha de trigo (g) & 100 & 702 & 146,28 & 23,32 & 2,7 \\
\hline Farinha de rosca $(\mathrm{g})$ & 100 & 824 & 147,1 & 22,8 & 14,8 \\
\hline
\end{tabular}




\begin{tabular}{|l|c|c|c|c|c|} 
Tomate (g) & 150 & 68 & 11,56 & 3,4 & 1,02 \\
\hline Sal $(\mathrm{g})$ & 17 & 0 & 0 & 0 & 0 \\
\hline Limão $(\mathrm{ml})$ & 100 & 29 & 10 & 2 & 0 \\
\hline Água & 200 & 0 & 0 & 0 & 0 \\
\hline Molho de tomate $(\mathrm{g})$ & 340 & 137,20 & 30,6 & 1,36 & 1,02 \\
\hline Alho $(\mathrm{g})$ & 12 & 16,08 & 3,52 & 0,64 & 0,02 \\
\hline Caldo de camarão (g) & 30 & 5,1 & 0,03 & 0,03 & 0,54 \\
\hline TOTAL & $\mathbf{2 6 2 9}$ & $\mathbf{4 1 6 1 , 8 0}$ & $\mathbf{3 5 8 , 5 3}$ & $\mathbf{1 7 1 , 9 6}$ & $\mathbf{1 3 7 , 0 4}$ \\
\hline PORÇÃo & $\mathbf{1 0 0 g}$ & & \multicolumn{5}{|c|}{ VCT PORÇÃO (kcal): } & $\mathbf{1 5 8 , 3 0}$ \\
\hline
\end{tabular}

Verificando as receitas originais e seu alto índice de gorduras, calorias e sal, houve a necessidade de modificá-las (Tabela 5 e 6) para agregar qualidade nutricional ao prato. Analisando os resultados obtidos as preparações se tornaram light. De acordo com o Ministério da Saúde (BRASIL, 2005), light são aqueles alimentos que devem ter, no mínimo, 25\% a menos de algum componente calórico, seja açúcar, gordura, sal, entre outros. São aqueles que apresentam a redução de qualquer um de seus componentes tendo como referência o produto do mesmo tipo.

A alteração das receitas, retirando alguns ingredientes e substituindo outros por light, sem sal e produtos caseiros, foi necessária para que a preparação se enquadre nos conceitos de alimentação saudável e nas orientações do Ministério da Saúde e OMS.

Tabela 5. Composição nutricional do filé de tilápia com palmito e molho branco

\begin{tabular}{|l|c|c|c|c|c|}
\hline \multicolumn{1}{|c|}{ ITEM } & QTDE. & ENERGIA (kcal) & CHO (g) & PTN (g) & GORD (g) \\
\hline Filé de tilápia (g) & 1000 & 950 & 0 & 20 & 1,7 \\
\hline Palmito (conserva) (g) & 300 & 54 & 11,10 & 4,80 & 0,30 \\
\hline Cogumelo (conserva) (g) & 200 & 28 & 4,80 & 3,80 & 0,20 \\
\hline Alcaparra (g) & 20 & 7,40 & 0,97 & 0,54 & 0,97 \\
\hline Limão (ml) & 100 & 29 & 10 & 2 & 0 \\
\hline Azeite de ervas (ml) & 13 & 108 & 0 & 0 & 13,90 \\
\hline Cebola (g) & 200 & 63 & 11,2 & 3,2 & 0,60 \\
\hline Manteiga sem sal (g) & 30 & 226,20 & 0 & 0,42 & 24,98 \\
\hline
\end{tabular}




\begin{tabular}{|l|c|c|c|c|c|} 
Sal $(\mathrm{g})$ & 7 & 0 & 0 & 0 & 0 \\
\hline Farinha de trigo $(\mathrm{g})$ & 60 & 131,70 & 34,27 & 6,34 & 0,25 \\
\hline Salsinha $(\mathrm{g})$ & 10 & 4,30 & 0,85 & 0,32 & 0,06 \\
\hline Cebolinha $(\mathrm{g})$ & 10 & 2,98 & 0,54 & 0,16 & 0,02 \\
\hline Leite desnatado $(\mathrm{ml})$ & 600 & 216,60 & 30 & 21,6 & 0,60 \\
\hline TOTAL & $\mathbf{2 5 5 0}$ & $\mathbf{1 8 2 1 , 1 8}$ & $\mathbf{1 0 3 , 7 3}$ & $\mathbf{6 3 , 1 8}$ & $\mathbf{4 3 , 5 8}$ \\
\hline PORÇÃo & $\mathbf{1 0 0 g}$ & & \multicolumn{4}{|l|}{ VCT PORÇÃO (kcal): } & $\mathbf{7 1 , 4 1}$ \\
\hline
\end{tabular}

No Filé de tilápia com palmito e molho branco - foram reduzidos, modificados e retirados os seguintes ingredientes:

- Adicionado $200 \mathrm{~g}$ de cogumelos em conserva. Ajuda a encorpar a preparação, deixando-a saudável, pois possui pequenas quantidades de carboidratos, proteínas e gorduras, além de agregar sabor;

- Azeite, reduzido $17 \mathrm{ml}$ e modificado para azeite de ervas (adição de ervas). A redução foi feita para diminuir a quantidade de calorias e a adição de ervas, misturadas ao azeite foi para deixar o peixe mais saboroso, mantendo as benesses do azeite e para não colocar sal no peixe, pois este já tem sabor característico;

- Manteiga, redução de $120 \mathrm{~g}$ e modificada para manteiga sem sal. Além de ser muito calórica a manteiga não é aliada da saúde, principalmente em grandes quantidades, por isso foi reduzida. A alteração para manteiga sem sal é para chegar ao limiar aceitável pelos órgãos que regularizam o consumo de sal;

- Leite, modificado para leite desnatado, principalmente para diminuir a quantidade de gorduras.

- Creme de leite e requeijão cremoso, retirados completamente. Esses ingredientes servem para deixar a preparação um pouco mais saborosa, mas não são necessárias, pois mesmo light, possuem muita gordura e com a adição das ervas o sabor fica diferente mais é mantido;

- Sal, redução de 9g, para se adaptar as recomendações;

- Salsinha e cebolinha, adição de $10 \mathrm{~g}$ de cada, para agregar sabor e qualidade nutricional. 
Tabela 6. Composição nutricional do filé de tilápia à parmegiana

\begin{tabular}{|l|c|c|c|c|c|}
\hline \multicolumn{1}{|c|}{ ITEM } & QTDE. & ENERGIA (kcal) & CHO (g) & PTN (g) & GORD (g) \\
\hline Filé de tilápia (g) & 1000 & 950 & 0 & 20 & 1,70 \\
\hline Mussarela (g) & 100 & 324,80 & 0 & 27,20 & 24,00 \\
\hline Cebola (g) & 100 & 31,50 & 5,60 & 1,60 & 0,30 \\
\hline Azeite de ervas (ml) & 13 & 108 & 0 & 0 & 13,90 \\
\hline Ovos (g) & 80 & 87,41 & 0 & 9,39 & 5,65 \\
\hline Farinha de trigo (g) & 100 & 351 & 73,14 & 11,66 & 1,45 \\
\hline Farinha de rosca (g) & 100 & 412 & 73,55 & 11,40 & 7,40 \\
\hline Tomate (g) & 800 & 160 & 27,20 & 8 & 2,40 \\
\hline Limão (ml) & 100 & 29 & 10 & 2 & 0 \\
\hline Açúcar (g) & 5 & 19,80 & 4,95 & 0 & 0 \\
\hline Sal (g) & 8 & 0 & 0 & 0 & 0 \\
\hline Água & 200 & 0 & 0 & 0 & 0 \\
\hline Pimentão Vermelho (g) & 20 & 6,20 & 1,20 & 0,26 & 0,04 \\
\hline Pimenta do reino (g) & 1 & 0,24 & 0,05 & 0,01 & 0 \\
\hline Pimenta dedo-moça(g) & 3 & 1,14 & 0,20 & 0,04 & 0,02 \\
\hline Manjericão(g) & 10 & 1,96 & 0,31 & 0,09 & 0,04 \\
\hline Salsinha (g) & 10 & 4,30 & 0,85 & 0,32 & 0,06 \\
\hline Cebolinha (g) & 10 & 2,98 & 0,54 & 0,16 & 0,02 \\
\hline Alho (g) & 12 & 16,08 & 3,52 & 0,64 & 0,02 \\
\hline \multicolumn{1}{|c|}{ TOTAL (g) } & $\mathbf{2 6 7 2}$ & $\mathbf{2 5 0 6 , 4 1}$ & $\mathbf{2 0 1 , 1 1}$ & $\mathbf{9 2 , 7 7}$ & $\mathbf{5 7 , 0 0}$ \\
\hline $\mathbf{1 0 0 g}$ & & $\mathbf{V C T}$ PORÇÃO (kcal): & $\mathbf{9 3 , 8 0}$ \\
\hline
\end{tabular}

No Filé de tilápia à parmegiana - foram reduzidos, modificados e retirados os seguintes ingredientes:

- Mussarela, redução de $200 \mathrm{~g}$. No filé a parmegiana a mussarela faz parte do prato, não sendo necessária grande quantidade, pelo fato de ter muita caloria e muita gordura;

- Alcaparra, retirado completamente. É um ingrediente desnecessário para esta preparação, além que possuir uma grande quantidade de sódio. 
- Azeite, reduzido $17 \mathrm{ml}$ e modificado para azeite de ervas; A redução foi feita para diminuir a quantidade de calorias e a adição de ervas, misturadas ao azeite foi para deixar o peixe mais saboroso, mantendo as benesses do azeite e para não colocar sal no peixe, pois este já tem sabor característico;

- Ovo, redução $20 \mathrm{~g}$ (1 gema). A utilização de um ovo inteiro e a clara de outro ovo é suficiente para empanar o peixe, portanto, a retirada da gema pode ser feita para reduzir gordura;

- Molho de tomate, retirado completamente. O molho industrializado além de possuir muitos conservantes e produtos que não são naturais, concentra muito sal, podendo ser substituído por molho de tomate caseiro;

- Tomate, adicionado 650g. Para substituir o molho industrializado e agregar sabor;

- Caldo de camarão, retirado. É um ingrediente que se utiliza para deixar mais saborosa, mas por ser industrializado e conter muito sal é importante retirá-lo, e substituí-lo por outros que também deixe a receita com sabor;

- Açúcar, adicionado $5 \mathrm{~g}$, para quebrar a acidez to tomate;

- Sal, reduzido 9g, para se adaptar aos conceitos de alimentação saudável;

- Adição de $10 \mathrm{~g}$ de salsinha, $10 \mathrm{~g}$ de cebolinha, $10 \mathrm{~g}$ de manjericão, $20 \mathrm{~g}$ de pimentão vermelho, $3 \mathrm{~g}$ de pimenta dedo-de-moça e $1 \mathrm{~g}$ de pimenta-doreino. Foi a opção encontrada para driblar a redução do sal e dos outros ingredientes.

\subsection{COMPARAÇÃO NUTRICIONAL DAS RECEITAS}

A comparação nutricional das receitas (tabela 7) foi feita para que se observe, com mais clareza, a diferença da composição nutricional em $100 \mathrm{~g}$ de preparação das receitas originais e modificadas e também verificar a redução dos componentes em porcentagem. 
Tabela 7. Comparação nutricional das receitas de filé de tilápia em $100 \mathrm{~g}$

\begin{tabular}{|c|c|c|c|c|c|}
\hline \multicolumn{1}{|c|}{ PREPARAÇÃO } & Kcal & CHO(g) & PTN(g) & GORD(g) & SÓDIO(mg) \\
\hline Molho branco original & 144,70 & 3,57 & 5,01 & 9,45 & 220 \\
\hline Molho branco modificado & 71,47 & 4,07 & 2,48 & 1,71 & 110 \\
\hline REDUÇÃO (\%) & $\mathbf{5 1 , 6 1}$ & $\mathbf{1 4 , 0 0}$ (aumento) & $\mathbf{5 0 , 5 0}$ & $\mathbf{8 1 , 9 2}$ & $\mathbf{5 0}$ \\
\hline Parmegiana original & 158,60 & 13,64 & 6,54 & 5,21 & 260 \\
\hline Parmegiana modificado & 93,90 & 7,53 & 3,66 & 2,14 & 120 \\
\hline REDUÇÃO (\%) & $\mathbf{4 0 , 7 9}$ & $\mathbf{4 4 , 7 9}$ & $\mathbf{5 3 , 2 1}$ & $\mathbf{5 8 , 9 2}$ & $\mathbf{5 3 , 8 5}$ \\
\hline
\end{tabular}

O Ministério da Saúde (BRASIL, 2005) recomenda a utilização de até $2.000 \mathrm{mg}$ de sódio para pessoas saudáveis, menos idosos e crianças, pois nessas idades a ingestão deve ser diferenciada. As modificações das receitas foram feitas de acordo com a normatização do MS, e houve uma redução maior que $50 \%$ nas duas preparações, tendo o filé de tilápia com molho branco 110 $\mathrm{mg}$ de sódio em $100 \mathrm{~g}$ e o filé de tilápia à parmegiana $120 \mathrm{mg}$ de sódio em $100 \mathrm{~g}$.

A Sociedade Brasileira de Alimentação e Nutrição (SBAN) recomenda que os nutrientes ingeridos diariamente estejam assim divididos: Proteínas, 10 a 12\%; Lipídios, 20 a 25\%; e carboidratos, 60 a 70\%. Para tanto, foi feito o cálculo da distribuição de macronutrientes das duas receitas, para verificar a porcentagem desses nutrientes em $100 \mathrm{~g}$ de preparação (Figura 11). 


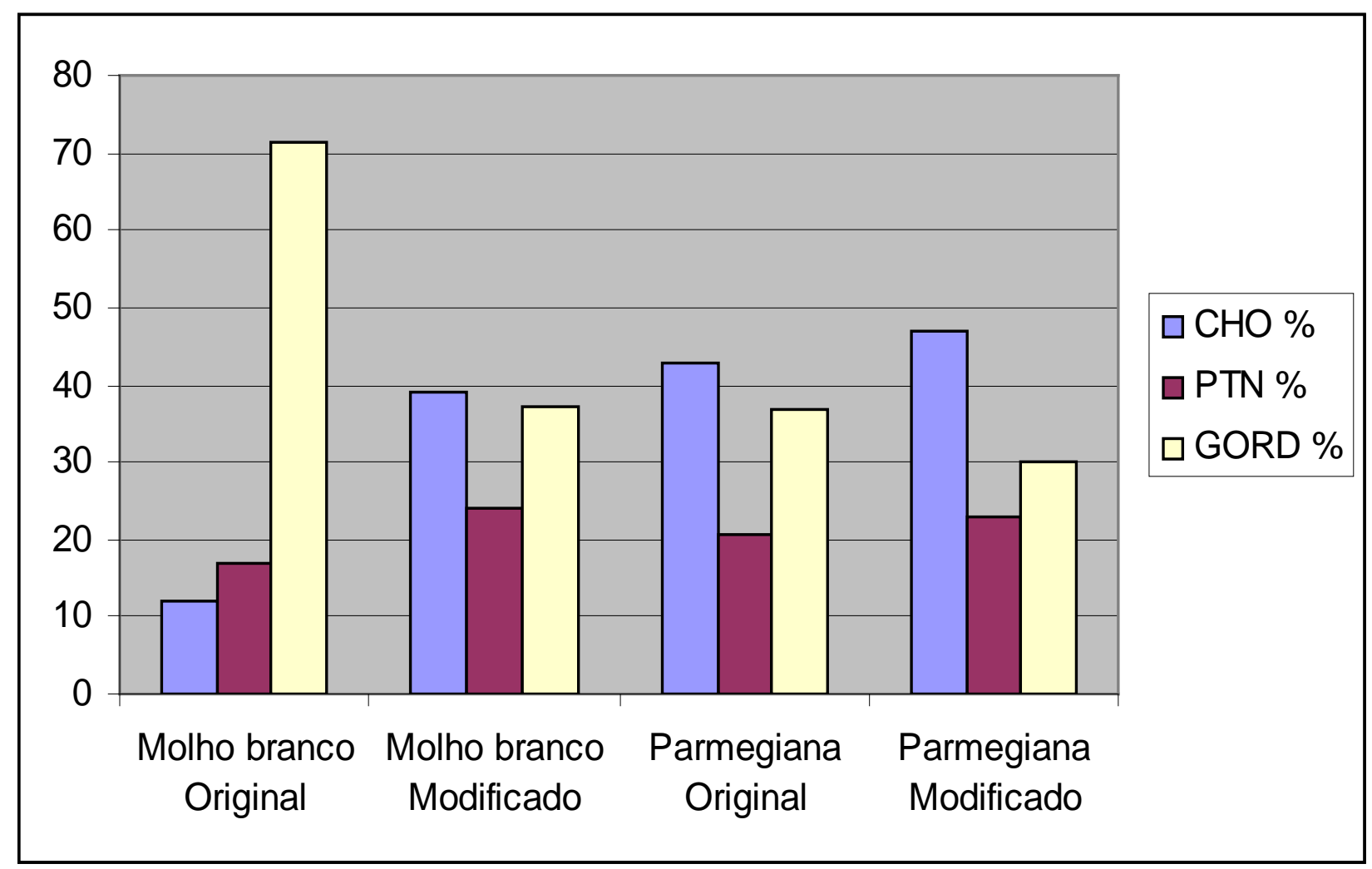

Figura 11. Distribuição de Macronutrientes (\%)

\subsection{ANÁLISE SENSORIAL}

5.2.1. Filé de tilápia com palmito e molho branco modificado

A análise sensorial das receitas modificadas foi feita para detectar a popularidade das preparações. $O$ prato foi provado e analisado por trinta clientes do restaurante, dentre eles 12 (doze) homens e 18 (dezoito) mulheres, a idade entre 18 e 76 anos, média de idade 39,63 anos e 7 (sete) deles hipertensos (Apêndice 3), e a figura 12 demonstra a freqüência das notas avaliadas.

Os dados da figura 12 estão representados no gráfico aranha apresentado na figura 13 , neste gráfico pode-se verificar que a popularidade do prato foi alta, ou seja, $100 \%$ de aceitação. 


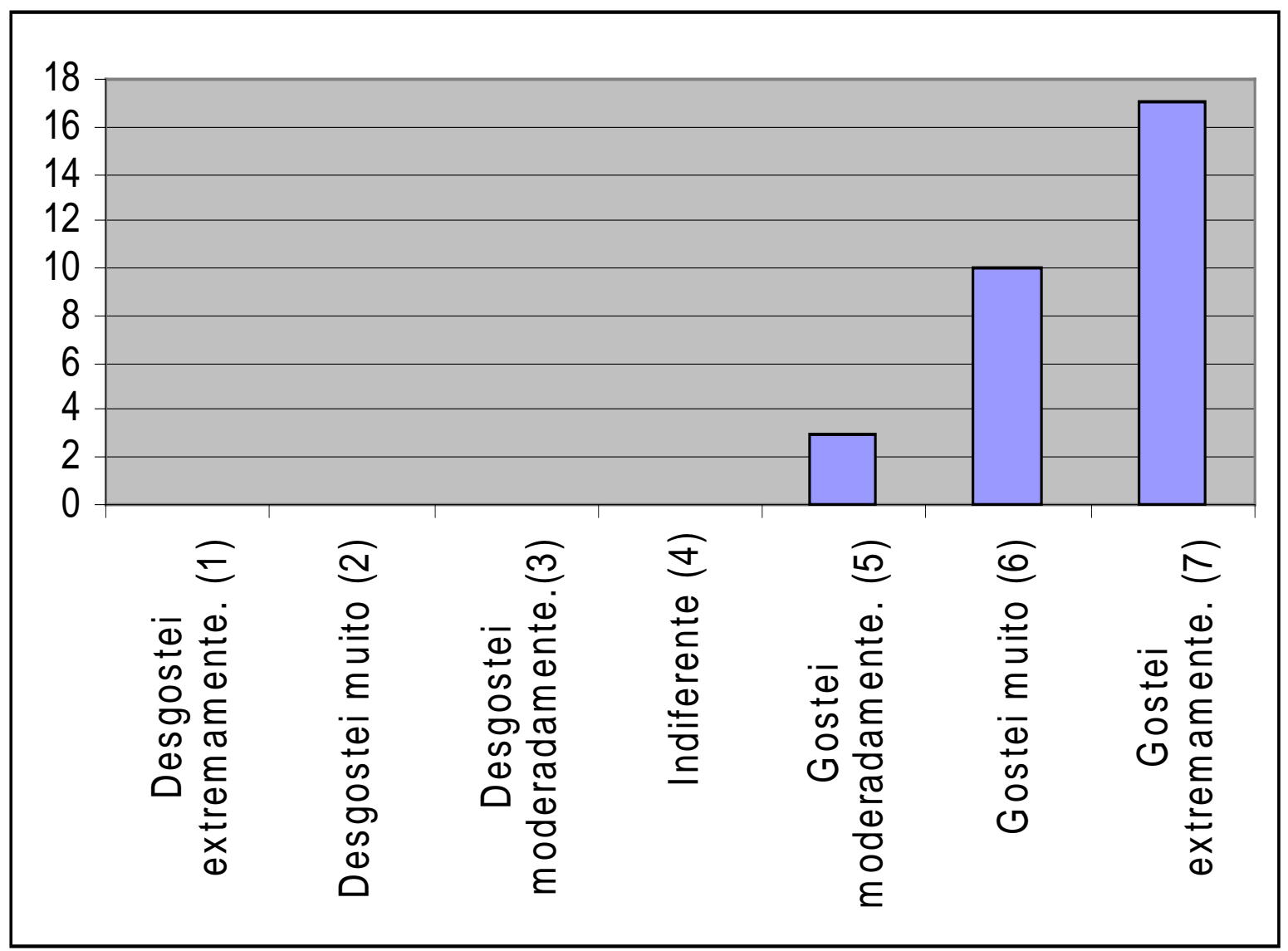

Figura 12. Tabela de escores de diferente formulação de filé de tilápia com palmito e molho branco.

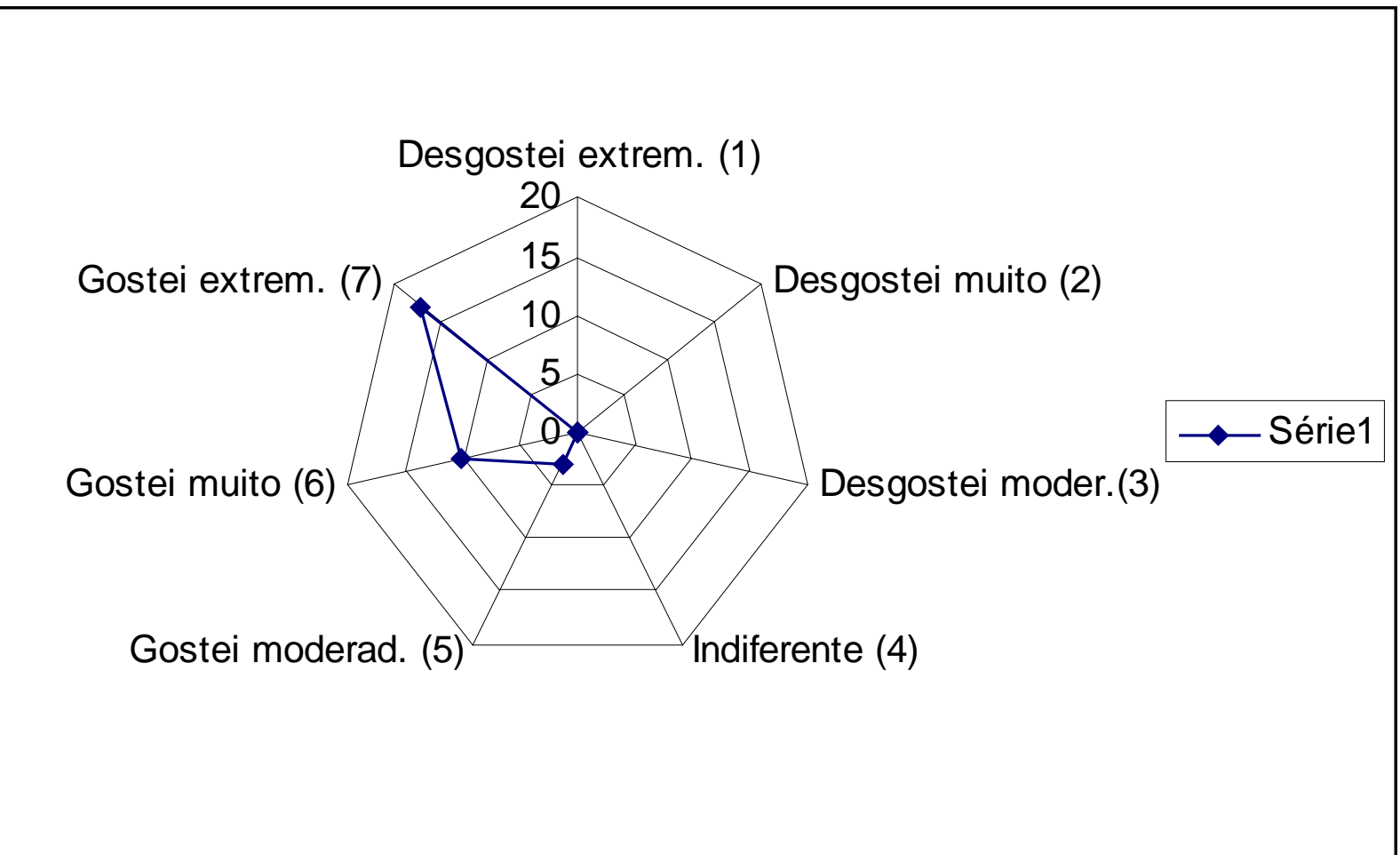

Figura 13. Gráfico aranha da análise sensorial do filé de tilápia com palmito e molho branco. 
Todos os 30 provadores aprovaram a receita, tendo $10 \%$ marcado a opção gostei moderadamente, 33,33\% a opção gostei muito e 56.67\% a opção gostei extremamente.

5.2.2. Filé de tilápia à parmegiana

O prato foi provado e analisado por trinta clientes do restaurante, dentre eles 11 homens e 19 mulheres, com idade entre 18 e 75 anos, média de idade 38,23 anos, e 5 deles hipertensos (Apêndice 3) a figura 14 demonstra a freqüência das notas avaliadas.

Os dados da figura 14 estão representados no gráfico aranha (Figura 15), neste gráfico pode-se verificar que a popularidade do prato foi alta, $89,5 \%$ de aceitação.

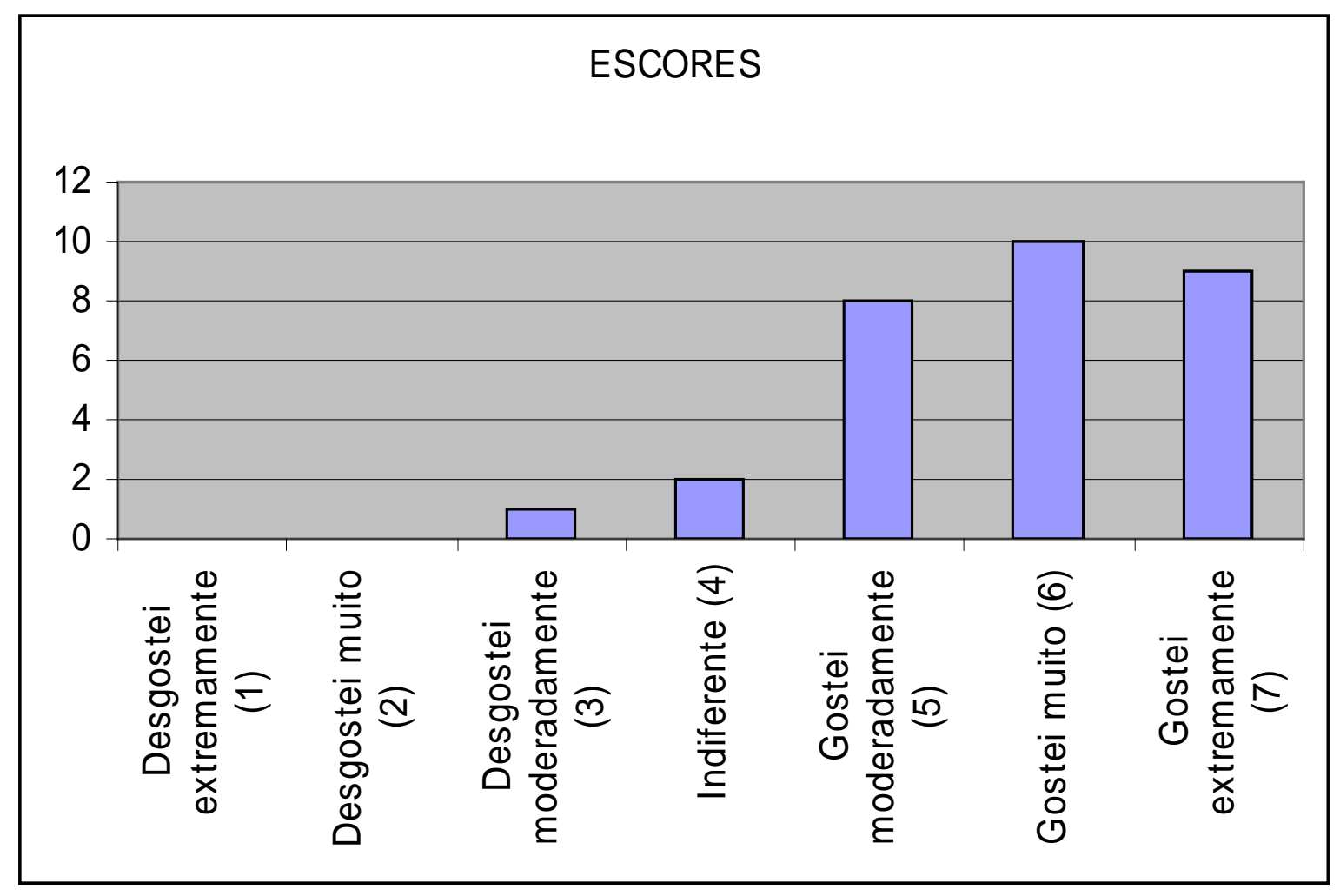

Figura 14. Tabela de escores de diferentes formulações de filé de tilápia à parmegiana. 


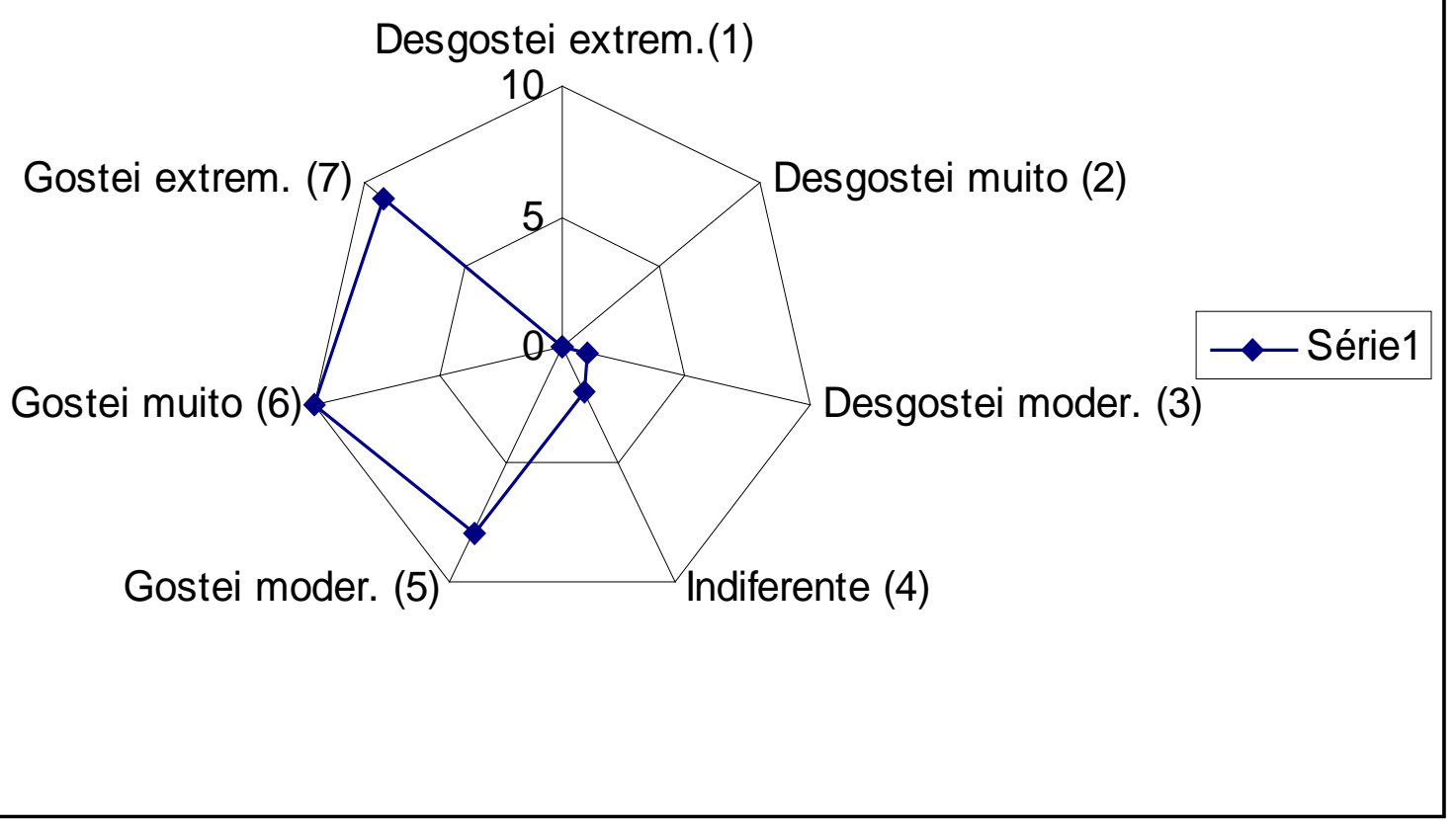

Figura 15. Gráfico aranha da análise sensorial do filé de tilápia à parmegiana

Dos 30 provadores apenas 3 não marcaram as opções "gostei", sendo, 3,33 \% desgostei moderadamente e 6,67\% indiferente. A opção gostei moderadamente equivale a $26,27 \%$ dos participantes, já a opção gostei muito representa $33,33 \%$ e gostei extremamente responsável por $30 \%$ dos participantes. 


\section{CONCLUSÃO}

O conceito de alimentação saudável está passando por uma inovação e, com ele, o surgimento de uma nova pirâmide alimentar. Ficaram estabelecidos novos padrões no consumo de proteínas, como o de carne vermelha que deve ser consumido com moderação e substituído por peixes, aves e ovos, e que o sal deve ser diminuído ou até retirado, trocando por ervas e condimentos.

A população está aprendendo que comer bem é um hábito que não deve ser isolado, conseqüentemente, deve fazer parte do cotidiano. Isso está gerando um aumento na ingestão de peixe, e com isso o crescimento da atividade da piscicultura. No Brasil, a criação de tilápia merece destaque, isso porque é um peixe com baixo teor de gordura, carne saborosa e de aparência agradável, que está cada vez mais fazendo parte do cardápio dos brasileiros.

No entanto, um prato que contenha peixe não é necessariamente saudável. Faz-se necessário uma avaliação do que é consumido, e que em grande parte, os ingredientes utilizados podem ser substituídos para que a preparação seja saborosa e esteja de acordo com os novos conceitos de alimentação balanceada.

A modificação de receitas foi realizada segundo os conceitos de uma preparação saudável. As receitas propostas foram testadas e avaliadas sensorialmente.

$\mathrm{Na}$ análise sensorial o prato de Filé de Tilápia com palmito e molho branco teve uma aceitação de $100 \%$. Isso se deve pelo fato da preparação ser grelhada, coberta por molho branco e conservas de vegetais com sabor destacado como palmito, cogumelo e alcaparra. A adição de ervas com o intuito de realçar o sabor e substituir a sensação que o sal trás agregou mais sabor à preparação.

O Filé de Tilápia à parmegiana obteve aceitação de $89,50 \%$, o que também caracteriza alta aceitabilidade, considerando-se como aprovação a aceitabilidade acima de $80 \%$. A principal alteração foi assar o peixe ao invés de fritá-lo, o que acabou tirando um pouco da textura crocante que a gordura agrega à preparação no momento da fritura. A adição de ervas, a troca do 
molho de tomate industrializado por molho caseiro e a permanência, mesmo que reduzida, da mussarela fez o prato ser bem aceito.

Com isso, verifica-se que a modificação de receitas é possível a partir do emprego de técnicas culinárias adequadas ao tipo de preparação que se deseja obter. 


\section{BIBLIOGRAFIA}

AKUTSU RC, BOTELHO RA, CAMARGO EB, SÁVIO KEO, ARAÚJO WC. Adequação das boas práticas de fabricação em serviços de alimentação. Rev Nutr. 2005; 18(5):669-80.

BRESSAN, Maria Cristina. Tecnologia de pós colheita em peixes. Lavras UFLA/FAEPE, 2001.

BRUGGER, A. M.; CRUZ JÚNIOR, C.A.; ASSAD, L.T. Produção de Tiápias: Manual de Orientação. Seminário Novos Rumos para o Cooperativismo Pesqueiro. RIO COOPERATIVO 2000. Brasília.

CASTAGNOLLI, Newton. Piscicultura de água doce. Jaboticabal: FUNEP. 1992.

FILHO, Evoy Zaniboni. Aqüicultura: experiências brasileiras. Florianópolis, SC: Multitarefa, 2003.

KUBITZA, Fernando. Tilápia e planejamento na produção comercial. Jundiaí: F. Kubitza, 2000.

PESCA, Secretaria Especial de Agricultura e Pesca. Aqüicultura no Brasil: o desafio é crescer. Brasília, 2008.

\section{SITES}

AGRONEGÓCIO. Disponível em http://www.portaldoagronegocio.com.br. Acesso em 10/06/2008 às 17h00min.

CAPES. Disponível em http://www.capes.gov.br. Acesso em 05/04/2008 às $16 \mathrm{~h} 48 \mathrm{~min}$ e em 10/06/2008 às $15 \mathrm{~h} 35 \mathrm{~min}$. 
FAST FISH - Dados nutricionai. Disponível em http://www.fastfish.com.br/. Acesso em 15/05/2008 às 10h18min.

FAO - Food and Agriculture Organization. Disponível em http://www.fao.org/. Acesso em 10/06/2008 às $13 \mathrm{~h} 41 \mathrm{~min}$.

GLOBO. Disponível em http://www.globo.com/maisvoce. Acesso em 08/05/2008 às 09h06min.

IBAMA - Secretaria de recursos pesqueiros. Disponível em http://www.ibama.gov.br/recursos-pesqueiros/index.php. Acesso em $14 / 05 / 2008$ às $13 \mathrm{~h} 20 \mathrm{~min}$.

IBGE - Informações estatísticas. Disponível em http://www.ibge.gov.br. Acesso em 16/06/2008 às 15h40min.

IBGE - POF - Pesquisas de Orçamentos Familiares. Disponível em http://www.ibge.gov.br/home/presidencia/noticias/19052004pof2002html.shtm. Acesso em 20/06/2008 às 15 h00min.

INSTITUTO AHAU. Disponível em http://www.ahau.org/salamigoinimigo. Acesso em 15/06/2008 às 11h05min.

MS - Ministério da Saúde: Nutrição. Disponível em http:// www.saude.gov.br/nutricao. Acesso em 06/04/2008 às 17h45min.

PEIXE NA REDE. Disponível em http://www.peixenarede.com.br. Acesso em $05 / 05 / 2008$ às $10 \mathrm{~h} 22 \mathrm{~min}$.

SAÚDE TOTAL. Disponível em http://www.saudetotal.com. Acesso em $15 / 06 / 2005$ às $13 \mathrm{~h} 55 \mathrm{~min}$. 
SCIELO. Disponível em http://www.scielo.br. Acesso em 09/04/2008 às $10 \mathrm{~h} 20 \mathrm{~min}$ e em 01/07/2008 às 20h32min.

SOCIEDADE BRASILEIRA DE CARDIOLOGIA. Disponível em http://prevencao.cardiol.br. Acesso em 18/06/2008 às 18h38min.

USDA - Departamento de Agricultura dos Estados Unidos da América. Disponível em http://www.usda.gov. Acesso em 19/06/2008 às 19h10min. 
APÊNDICES

APÊNDICE 1 - FICHAS DE AVALIAÇÃO DE ACEITABILIDADE SENSORIAL 


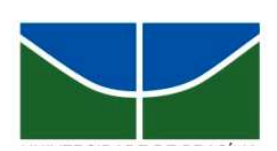

FICHA DE AVALIAÇÃO DE ACEITABILIDADE SENSORIAL

Esta ficha tem o intuito de avaliar sensorialmente as receitas de filé de tilápia.

A pesquisa faz parte do trabalho de conclusão do curso de pós-graduação lato sensu de GASTRONOMIA DE SAÚDE ministrado pelo CET (Centro de Excelência em Turismo) da UnB (Universidade de Brasília).

Idade:

Sexo: Feminino

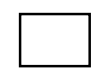

Masculino

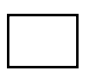

Hipertenso: Sim

Não

Por favor, prove a amostra de FILÉ DE TILÁPIA AO MOLHO DE PALMITO E MOLHO BRANCO, reflita seu julgamento e assinale sua nota de acordo com a escala abaixo:

$\square$ Gostei extremamente

$\square$ Gostei muito

$\square$ Gostei moderadamente

$\square$ Indiferente

$\square$ Desgostei moderadamente

$\longrightarrow$ Desgostei muito

$\square$ Desgostei extremamente 


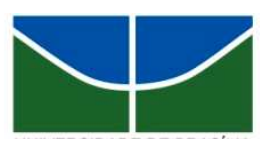

\section{FICHA DE AVALIAÇÃO DE ACEITABILIDADE SENSORIAL}

Esta ficha tem o intuito de avaliar sensorialmente as receitas de filé de tilápia. A pesquisa faz parte do trabalho de conclusão do curso de pós-graduação lato sensu de GASTRONOMIA DE SAÚDE ministrado pelo CET (Centro de Excelência em Turismo) da UnB (Universidade de Brasília).

Idade:

Sexo: Feminino

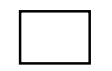

Masculino

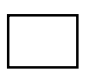

Hipertenso: Sim

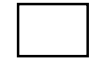

Não

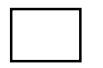

Por favor, prove a amostra de FILÉ DE TILÁPIA À PARMEGIANA, reflita seu julgamento e assinale sua nota de acordo com a escala abaixo:

$\square$ Gostei extremamente

$\square$ Gostei muito

$\square$ Gostei moderadamente

$\square$ Indiferente

$\square$ Desgostei moderadamente

Desgostei muito

$\square$ Desgostei extremamente 
APÊNDICE 2 - FICHAS TÉCNICAS DE PREPARAÇÃO (FTP)

I) RECEITAS ORIGINAIS 
Tipo de Produto (Grupo):

Item:

Rendimento (g): $\quad 2790$

FICHA TÉCNICA DE PREPARO

FILÉ DE TILÁPIA COM PALMITO E MOLHO BRANCO

Porção(Medida Caseira):

\begin{tabular}{|c|c|c|c|c|c|c|}
\hline & & & Medida Caseira): & filé & & \\
\hline Ingredientes & PB $(\mathrm{g}, \mathrm{ml})$ & $\mathrm{PL}(\mathrm{g}, \mathrm{ml})$ & Und. Compra (g,ml) & FC & PCB & PCL \\
\hline Filé de tilápia & 1000 & 1000 & $1000 \mathrm{~g}$ & 1,00 & 35,71 & 35,71 \\
\hline Palmito em conserva & 300 & 300 & $300 \mathrm{~g}$ & 1,00 & 10,71 & 10,71 \\
\hline Alcaparra & 20 & 20 & $65 \mathrm{~g}$ & 1,00 & 0,71 & 0,71 \\
\hline Azeite & 30 & 30 & $500 \mathrm{ml}$ & 1,00 & 1,07 & 1,07 \\
\hline Cebola & 260 & 200 & $1000 \mathrm{~g}$ & 1,30 & 9,29 & 7,14 \\
\hline Limão & 300 & 100 & $1000 \mathrm{~g}$ & 3,00 & 10,71 & 3,57 \\
\hline Sal & 16 & 16 & $1000 \mathrm{~g}$ & 1,00 & 0,57 & 0,57 \\
\hline Manteiga & 150 & 150 & $250 \mathrm{~g}$ & 1,00 & 5,36 & 5,36 \\
\hline Farinha de trigo & 60 & 60 & $1000 \mathrm{~g}$ & 1,00 & 2,14 & 2,14 \\
\hline Leite & 600 & 600 & $1000 \mathrm{ml}$ & 1,00 & 21,43 & 21,43 \\
\hline Creme de leite & 200 & 200 & $200 \mathrm{~g}$ & 1,00 & 7,14 & 7,14 \\
\hline Requeijão cremoso & 250 & 250 & $250 \mathrm{~g}$ & 1,00 & 8,93 & 8,93 \\
\hline
\end{tabular}

\section{Modo de Preparo:}

Espremer os limões, fazendo um suco. Picar as cebolas em pedaços bem pequenos. Temperar os filés de tilápia numa vasilha, com sal e suco de limão, regar com azeite uma frigideira antiaderente e grelhar o peixe. Em outra panela grelhar com manteiga, o palmito e cebolas picadas com as alcaparras, colocar o molho branco e o requeijão e levar para gratinar.

\section{Modo de Preparo Molho Branco:}

Numa panela em fogo brando derreta manteiga, acrescente farinha de trigo e com o auxílio de um batedor de arame (fuet), bata vigorosamente por 3 minutos. Ainda batendo acrescente leite. Bata até obter consistência lisa. Aumente o fogo e deixe ferver por +/- 3 minutos (batendo sempre). Coloque a folha de louro na cebola e espete com os cravos. Tempere com sal a gosto, diminua o fogo e cozinhe por alguns minutos, mexendo de vez em quando para não grudar no fundo da panela. Junte pimenta branca, noz-moscada ralada a gosto e creme de leite. Desligue o fogo e bata por 3 minutos. 
Informações Técnicas

Fcy:

IA:

№ de porções:

0,95

$\mathrm{NA}^{*}$

Densidade $(\mathrm{g} / \mathrm{ml})$ :
Percentual de Macronutrientes

CHO: $11,96 \%$

PTN: $\quad 16,79 \%$

LIP: $\quad 71,25 \%$

$100,00 \%$ 
FICHA TÉCNICA DE PREPARO

Tipo de Produto (Grupo):

Item:

Rendimento (g):
FILÉ DE TILÁPIA À PARMEGIANA

2325

Porção (g):

Porção (Medida Caseira): 
Informações Técnicas

Fcy:

IA:

№ de porções:

Densidade $(\mathrm{g} / \mathrm{ml})$ :

\begin{tabular}{|c|c|}
\hline CHO: & $42,76 \%$ \\
\hline PTN: & $20,50 \%$ \\
\hline LIP: & $36,74 \%$ \\
\hline
\end{tabular}


II) RECEITAS MODIFICADAS 
FICHA TÉCNICA DE PREPARO

Tipo de Produto (Grupo):

Item:

Rendimento (g):
FILÉ DE TILÁPIA COM PALMITO E MOLHO BRANCO

2415
Porção (g):

Porção (Medida Caseira):
100

\begin{tabular}{|c|c|c|c|c|c|c|}
\hline \multicolumn{7}{|c|}{ Porçao (IMledıda Caseıra): 1 tile } \\
\hline Ingredientes & PB $(\mathrm{g}, \mathrm{ml})$ & PL $(g, m l)$ & Und. Compra (g,ml) & FC & PCB & PCL \\
\hline Filé de tilápia & 1000 & 1000 & $1000 \mathrm{~g}$ & 1,00 & 41,67 & 41,67 \\
\hline Palmito em conserva & 300 & 300 & $300 \mathrm{~g}$ & 1,00 & 12,50 & 12,50 \\
\hline Cogumelo em conserva & 200 & 200 & $200 \mathrm{~g}$ & 1,00 & 8,33 & 8,33 \\
\hline Alcaparra & 20 & 20 & $65 \mathrm{~g}$ & 1,00 & 0,83 & 0,83 \\
\hline Azeite de ervas & 13 & 13 & $500 \mathrm{ml}$ & 1,00 & 0,54 & 0,54 \\
\hline Cebola & 260 & 200 & $1000 \mathrm{~g}$ & 1,30 & 10,83 & 8,33 \\
\hline Limão & 300 & 100 & $1000 \mathrm{~g}$ & 3,00 & 12,50 & 4,17 \\
\hline Sal & 7 & 7 & $1000 \mathrm{~g}$ & 1,00 & 0,29 & 0,29 \\
\hline Manteiga sem sal & 30 & 30 & $250 \mathrm{~g}$ & 1,00 & 1,25 & 1,25 \\
\hline Farinha de trigo & 60 & 60 & $1000 \mathrm{~g}$ & 1,00 & 2,50 & 2,50 \\
\hline Leite desnatado & 600 & 600 & $1000 \mathrm{ml}$ & 1,00 & 25,00 & 25,00 \\
\hline Cebolinha & 10 & 10 & $1000 \mathrm{~g}$ & 1,00 & 0,42 & 0,42 \\
\hline Salsinha & 10 & 10 & $1000 \mathrm{~g}$ & 1,00 & 0,42 & 0,42 \\
\hline TOTAL & 2810 & 2550 & & & & \\
\hline
\end{tabular}

\section{Modo de Preparo:}

Espremer os limões fazendo um suco. Picar a cebola em pedaço bem pequenos. Temperar os filés de tilápia numa vasilha, com suco de limão e deixar descansando por uns 3 minutos, depois colocar $10 \mathrm{ml}$ do azeite de ervas e deixar descansar por mais uns 3 minutos. Grelhar o peixe com o restante do azeite de ervas. Lavar bem e escorrer o palmito, o cogumelo e as alcaparras. Grelhar com manteiga, o palmito e cebolas picadas com as alcaparras e 0 cogumelos, colocar o molho branco e levar para gratinar.

\section{Modo de Preparo Molho Branco:}

Numa panela em fogo brando derreta manteiga, acrescente farinha de trigo e com o auxílio de um batedor de arame (fuet), bata vigorosamente por 3 minutos. Ainda batendo acrescente leite. Bata até obter consistência lisa. Aumente o fogo e deixe ferver por $+/-3$ minutos (batendo sempre). Coloque a folha de louro na cebola e espete com os cravos. Tempere com sal a gosto, diminua o fogo e cozinhe por alguns minutos, mexendo de vez em quando para não grudar no fundo da panela. Junte pimenta branca, noz-moscada ralada a gosto. Desligue o fogo e bata por 3 minutos. 
Informações Técnicas

Fcy:

IA:

№ de porções:

0,95

$\mathrm{NA}^{*}$

Densidade $(\mathrm{g} / \mathrm{ml})$ :
Percentual de Macronutrientes

CHO: $\quad 39,15 \%$

PTN: $\quad 23,85 \%$

LIP: $\quad 37,00 \%$ $100,00 \%$ 
Item:

Rendimento (g):
Tipo de Produto (Grupo):

2395

FICHA TÉCNICA DE PREPARO

FILÉ DE TILÁPIA À PARMEGIANA

$2395 \quad$ Porção $(\mathrm{g}): \quad 100$

Porção (Medida Caseira): 1 file

\begin{tabular}{|c|c|c|c|c|c|c|}
\hline \\
\hline Ingredientes & PB $(\mathrm{g}, \mathrm{ml})$ & $\mathrm{PL}(\mathrm{g}, \mathrm{ml})$ & Und. Compra (g,ml) & FC & PCB & PCL \\
\hline Filé de tilápia & 1000 & 1000 & $1000 \mathrm{~g}$ & 1,00 & 43,48 & 43,48 \\
\hline Mussarela & 100 & 100 & $1000 \mathrm{~g}$ & 1,00 & 4,35 & 4,35 \\
\hline Azeite & 13 & 13 & $500 \mathrm{ml}$ & 1,00 & 0,57 & 0,57 \\
\hline Cebola & 130 & 100 & $1000 \mathrm{~g}$ & 1,30 & 5,65 & 4,35 \\
\hline Ovo & 110 & 80 & 1 duzia & 1,38 & 4,78 & 3,48 \\
\hline Tomate & 1000 & 800 & $1000 \mathrm{~g}$ & 1,25 & 43,48 & 34,78 \\
\hline Limão & 300 & 100 & $1000 \mathrm{~g}$ & 3,00 & 13,04 & 4,35 \\
\hline Farinha de trigo & 150 & 100 & $1000 \mathrm{~g}$ & 1,50 & 6,52 & 4,35 \\
\hline Farinha de rosca & 150 & 100 & $500 \mathrm{~g}$ & 1,50 & 6,52 & 4,35 \\
\hline Sal & 8 & 8 & $1000 \mathrm{~g}$ & 1,00 & 0,35 & 0,35 \\
\hline Água & 200 & 200 & $1000 \mathrm{ml}$ & 1,00 & 8,70 & 8,70 \\
\hline Açúcar & 5 & 5 & $5000 \mathrm{~g}$ & 1,00 & 0,22 & 0,22 \\
\hline Salsinha & 11 & 10 & $1000 \mathrm{~g}$ & 1,10 & 0,48 & 0,43 \\
\hline \multirow{6}{*}{$\begin{array}{l}\text { Cebolinha } \\
\text { Manjericão } \\
\text { Pimenta do reino } \\
\text { Pimenta dedo de moça } \\
\text { Pimentão vermelho } \\
\text { Alho }\end{array}$} & 11 & 10 & $1000 \mathrm{~g}$ & 1,10 & 0,48 & 0,43 \\
\hline & 12 & 10 & $1000 \mathrm{~g}$ & 1,20 & 0,52 & 0,43 \\
\hline & 1 & 1 & $1000 \mathrm{~g}$ & 1,00 & 0,04 & 0,04 \\
\hline & 5 & 3 & $1000 \mathrm{~g}$ & 1,67 & 0,22 & 0,13 \\
\hline & 30 & 20 & $1000 \mathrm{~g}$ & 1,50 & 1,30 & 0,87 \\
\hline & 13 & 12 & $1000 \mathrm{~g}$ & 1,08 & 0,57 & 0,52 \\
\hline
\end{tabular}

3249

2672

Modo de Preparo: 
Lave bem os tomates e retire a pele e a semente. Corete a cebola e o tomate em pequenos pedaços. Esprema os limões. Em uma panela, coloque 0 azeite, a cebola picada, o alho amassado, deixe fritar até dourar, logo após coloque os tomates e deixe refogar por alguns minutos. Acrescente o molho de tomate, os tabletes de caldo de camarão e as alcaparras, refoque tudo por alguns instantes. Logo após acrescente a água, $5 \mathrm{~g}$ de sal e deixe ferver por 10 minutos. $\mathrm{O}$ molho estará pronto. Em uma vasilha, tempere os filés de tilápia, com o caldo de limão e $7 \mathrm{~g}$ restantes do sal. Passe os filés de tilápia após o tempero na farinha de tripo, depois nos ovos batidos e em seguida na farinha de rosca. Coloque o óleo em uma frigideira e frite-os a temperatura de $150^{\circ} \mathrm{C}$. Disponha os filés fritos em uma refratária.Cubra o peixe com a mussarela e acrescente o molho de tomate por cima. Leve ao forno por 10 a 15 minutos a uma temperatura de $180^{\circ} \mathrm{C}$.

\section{Informações Técnicas}

Fcy:

IA:

№ de porções:

Densidade $(\mathrm{g} / \mathrm{ml})$ :

\section{Percentual de Macronutrientes}

$\begin{array}{rr}\text { CHO: } & 42,76 \% \\ \text { PTN: } & 20,50 \% \\ \text { LIP: } & 36,74 \%\end{array}$

$100,00 \%$ 
APÊNDICE 3 - TABULAÇÃO DOS DADOS DA ANÁLISE SENSORIAL 
PRATO 1 - FILÉ DE TILÁPIA COM PALMITO E MOLHO BRANCO

\begin{tabular}{|c|c|c|c|}
\hline SEXO & IDADE & HIPERTENSO & NOTA \\
\hline MASCULINO & 18 & NÂO & 1 \\
\hline FEMININO & 22 & NÃO & 1 \\
\hline FEMININO & 21 & NÂO & 2 \\
\hline FEMININO & 55 & SIM & 1 \\
\hline MASCULINO & 45 & SIM & 2 \\
\hline MASCULINO & 33 & NÃO & 1 \\
\hline MASCULINO & 23 & NÂO & 2 \\
\hline FEMININO & 29 & NÃO & 1 \\
\hline FEMININO & 40 & NÃO & 2 \\
\hline MASCULINO & 47 & SIM & 3 \\
\hline FEMININO & 30 & NÃO & 1 \\
\hline FEMININO & 27 & NÃO & 1 \\
\hline FEMININO & 37 & NÃO & 1 \\
\hline MASCULINO & 19 & NÃO & 2 \\
\hline FEMININO & 72 & SIM & 2 \\
\hline MASCULINO & 68 & NÃO & 1 \\
\hline FEMININO & 27 & NÃO & 2 \\
\hline MASCULINO & 20 & NÂO & 1 \\
\hline MASCULINO & 63 & NÃO & 1 \\
\hline MASCULINO & 52 & SIM & 3 \\
\hline FEMININO & 41 & NÃO & 1 \\
\hline FEMININO & 18 & NÃO & 2 \\
\hline MASCULINO & 40 & NÃO & 1 \\
\hline FEMININO & 20 & NÃO & 3 \\
\hline FEMININO & 28 & NÃO & 2 \\
\hline FEMININO & 65 & SIM & 1 \\
\hline FEMININO & 42 & NÃO & 1 \\
\hline MASCULINO & 76 & SIM & 2 \\
\hline FEMININO & 60 & NÃO & 1 \\
\hline FEMININO & 51 & NÃO & 1 \\
\hline MÉDIA & 39,63333333 & MÉDIA & 1,533333333 \\
\hline
\end{tabular}

\section{PRATO 2 - FILÉ DE TILÁPIA À PARMEGIANA}




\begin{tabular}{|c|c|c|c|}
\hline MASCULINO & 26 & NÃO & 2 \\
\hline MASCULINO & 25 & NÃO & 3 \\
\hline FEMININO & 49 & SIM & 3 \\
\hline FEMININO & 19 & NÃO & 1 \\
\hline FEMININO & 20 & NÃO & 2 \\
\hline FEMININO & 24 & NÃO & 3 \\
\hline MASCULINO & 18 & NÃO & 4 \\
\hline MASCULINO & 48 & SIM & 3 \\
\hline FEMININO & 21 & NÃO & 1 \\
\hline FEMININO & 22 & NÃO & 1 \\
\hline FEMININO & 45 & NÃO & 2 \\
\hline MASCULINO & 75 & SIM & 3 \\
\hline FEMININO & 73 & NÃO & 2 \\
\hline MASCULINO & 53 & SIM & 5 \\
\hline FEMININO & 29 & NÃO & 2 \\
\hline FEMININO & 32 & NÃO & 1 \\
\hline MASCULINO & 30 & NÃO & 2 \\
\hline FEMININO & 18 & NÃO & 1 \\
\hline FEMININO & 27 & NÂO & 2 \\
\hline FEMININO & 61 & SIM & 3 \\
\hline FEMININO & 25 & NÃO & 1 \\
\hline MASCULINO & 38 & NÃO & 1 \\
\hline FEMININO & 35 & NÃO & 2 \\
\hline FEMININO & 41 & NÃO & 2 \\
\hline MASCULINO & 34 & NÃO & 3 \\
\hline FEMININO & 58 & NÃO & 4 \\
\hline FEMININO & 67 & SIM & 3 \\
\hline MASCULINO & 57 & SIM & 2 \\
\hline FEMININO & 33 & NÃO & 1 \\
\hline MASCULINO & 44 & NÂO & 1 \\
\hline MÉDIA & 38,23333333 & MÉDIA & 2,2 \\
\hline
\end{tabular}

